Article

\title{
Alcohol Dehydration by Extractive Distillation with Use of Aminoethers of Boric Acid
}

\author{
Alexander V. Klinov*, Alexander V. Malygin ${ }^{\mathbb{D}}$, Alina R. Khairullina, Sergey E. Dulmaev and \\ Ilsiya M. Davletbaeva *
}

Department of Chemical Process Engineering, Kazan National Research Technological University, 68 Karl Marx St., 420015 Kazan, Russia; mav@kstu.ru (A.V.M.); apelsinochka91@mail.ru (A.R.K.); impsble@gmail.com (S.E.D.)

* Correspondence: alklin@kstu.ru (A.V.K.); davletbaeva09@mail.ru (I.M.D.)

Received: 14 October 2020; Accepted: 13 November 2020; Published: 16 November 2020

\begin{abstract}
Aminoethers of boric acid (AEBA) were studied as potential extractants for the separation of aqueous-alcoholic azeotropic mixtures by extractive distillation. The conditions of vapor-liquid equilibrium in aqueous solutions of ethanol and isopropanol in the presence of AEBA were studied. The division of AEBA molecules into group components was proposed, and previously unknown geometric parameters of the boron group and the energetic pair parameters of the boron group with the alkane group, ether group, amine-3d group, and alcohol group were determined within the framework of the Universal Functional Group Activity Coefficient (UNIFAC) model. The modeling of the extractive rectification process of an ethanol-water mixture with AEBA as extractant has been carried out. The dependences of the cost function on the extractant flow rate, the residual water content in it and the number of theoretical trays were obtained. A technological scheme for ethanol dehydration has been proposed, and its technological characteristics have been calculated.
\end{abstract}

Keywords: extraction; vapor-liquid equilibrium; aqueous solution; UNIFAC model

\section{Introduction}

Anhydrous alcohols are widely used in the chemical industry as raw materials for the chemical synthesis of esters and ethers, as well as solvents in the production of paints, cosmetics, aerosols, perfumery, drugs, food and many other industrial areas. In addition, mixtures of anhydrous alcohols such as ethanol, isopropanol and gasoline are used as biofuels, increasing the octane number of gasoline and raising its combustion rate. Consequently, this reduces the level of carbon monoxide in the exhaust and reduces environmental pollution. In many cases of practical use of alcohols, their high purity is required, not less than $99 \mathrm{wt} \%$ [1]. It is known that many alcohols form azeotropic mixtures with water, for example, ethanol at a content of $95.5 \mathrm{wt} \%$, and isopropanol at $87.4 \mathrm{wt} \%$. Distillation (rectification) methods or their special types (extractive or azeotropic rectification) are traditionally used to separate water-alcohol mixtures. Such separation methods are energy intensive, require the use of extractants and additional equipment that are not always cheap, and the costs of their implementation largely determine the cost of the product (alcohol). Thus, this study is aimed at finding effective extractants capable of purposefully changing the relative volatility of the components of aqueous-alcoholic solutions, easily regenerating and having a low cost is relevant. Known extractants, solid salts and organic solvents used for the separation of water-alcohol mixtures have some disadvantages that limit their use for the production of anhydrous alcohols. The use of solid salts (solutions of salts of sodium nitrate, lithium chloride, sodium chloride, potassium chloride, calcium chloride, potassium iodide and potassium acetate) $[2,3]$ has problems associated with their corrosiveness and regeneration. Organic solvents used for the dehydration of alcohols (ethylene glycol, diethyl ether, benzene, pentane and 
glycerol) [4] are volatile and can contaminate the distillate. There are options for using salt solutions in organic solvents as extractants. Sometimes this approach gives a positive result during polar or non-polar systems separation [5-8]. Nevertheless, the low solubility of salts in organic solvents, with the remaining drawbacks listed above, limits the application of this approach.

There are known examples of hyperbranched polymers usage for the separation of mixtures, ethanol-water and tetrahydrofuran-water, using extractive rectification and solvent extraction, respectively $[9,10]$. Among them, there are only a few hyperbranched polymers currently commercially available that meet the requirements for extractants (low viscosity, low melting point, thermal stability and selectivity).

Recently, ionic liquids (IL) have also been used as separating agents in the process of extractive rectification [11-18]. Ionic liquids are a diverse group of salts that exist in liquid state at room temperature. Studies show that ILs are very effective extractants, but their industrial use is still limited by the high cost of their production.

In this work, we investigated the possibility of using aqueous-alcoholic solutions of aminoethers of boric acid (AEBA) as effective extractants for extractive distillation. As shown in our previous work [19], AEBA exhibit some properties similar to the properties of ionic liquids: the melting point is below $100{ }^{\circ} \mathrm{C}$, they are practically non-volatile, their aqueous solutions have high electrical conductivity, and the azeotrope is removable when added to aqueous-alcoholic solutions. In contrast to imidazole ionic liquids, AEBA have a much lower production cost, which makes them promising extractants for the separation of water-alcohol mixtures by rectification. To assess the efficiency of AEBA as extractive agents, the following problems were solved in this work: the conditions of vapor-liquid equilibrium in aqueous solutions of ethanol-water were identified, isopropanol-water in the presence of AEBA was studied, a method for calculating the activity coefficients of components in such mixtures was proposed, the calculations of the ethanol dehydration technological scheme were carried out, and its technological characteristics were determined.

\section{Materials and Methods}

\subsection{Materials}

All glycols, i.e., diethylene glycol (DEG) and triethylene glycol (TEG) were purchased from PJSC Nizhnekamskneftekhim (Nizhnekamsk, Russia). Triethanolamine (TEA) was purchased from OJSC Kazanorgsintez. Boric acid (99.99 wt \%) was purchased from Sigma-Aldrich. Glycols were additionally dehydrated at a vacuum depth of 1-3 $\mathrm{mm} \mathrm{Hg}$ and a temperature of $90{ }^{\circ} \mathrm{C}$ to a moisture content less than $0.01 \mathrm{wt} \%$. These conditions were chosen experimentally, and they ensure the constancy of the residual water content. For carrying out distillation experiments, ethanol (96.3 wt \%) and isopropanol (99.8 wt \%, JSC "EKOS-1") were used. For the preparation of aqueous solutions and mixtures, deionized water was used, prepared on the Osmodemi 12 installation.

\subsection{Synthesisprocess}

Aminoethers of boric acid based on di- and tri-ethylene glycol (AEBA-DEG/AEBA-TEG) were obtained in one step. The calculated amount of triethanolamine, boric acid and DEG/TEG was added to a three-necked round bottom flask at a molar ratio of [TEA]:[ $\left.\mathrm{H}_{3} \mathrm{BO}_{3}\right]:[\mathrm{DEG} / \mathrm{TEG}]=1: 6: 12$. The use of such molar ratio was justified in previous work [19]. The mass of boric acid (6 mol) was $2.793 \mathrm{~g}$, and that of triethanolamine ( $1 \mathrm{~mol})$ was $1.124 \mathrm{~g}$. The mass of DEG/TEG (12 mol) was $9.644 \mathrm{~g} / 13.485 \mathrm{~g}$, respectively. The reaction mixture was heated to $90{ }^{\circ} \mathrm{C}$ with heating rate of $2{ }^{\circ} \mathrm{C} \mathrm{min}-1$ at a residual pressure of $10 \mathrm{~mm} \mathrm{Hg}$ and was kept under these conditions for $2 \mathrm{~h}$. This time has been chosen experimentally, and it ensures the constancy of the residual water content involved in the structural organization of AEBA. The vacuum was created with an oil pump connected to a U-shaped moisture trap filled with zeolite. Since the dissolution rate is greater than the reaction rate, the mixing was carried out by the natural bubbling of water released during the reaction. 
The progress of the reaction was monitored by titration by determining the concentration of hydroxyl groups. When the number of hydroxyl groups reached the plateau, the synthesis was considered as completed. The synthesis product was placed into sealed jar. AEBA-TEG contained $3.96 \mathrm{wt} \%$ of water, and AEBA-DEG contained $4.97 \mathrm{wt} \%$ of water. The water content was measured using a volumetric titrator from Mettler Toledo V20 according to the Karl Fischer method.

\subsection{Preparation of Aqueous Solutions and Mixtures}

For the preparation of AEBA aqueous solutions and mixtures, deionized water was used. Samples were prepared on a ShincoADJ scales with a measurement error of $\pm 0.0001 \mathrm{~g}$.

\subsection{Determination of the Boiling Point}

To measure the boiling point of binary mixtures, the Swietoslavsky ebulliometer were used [20] (JSC "Khimlaborpribor"). The scheme of ebulliometer is shown in Scheme 1. The temperature was measured with an LT-300-N electronic thermometer (LLC Termeks) with an error of $\pm 0.05{ }^{\circ} \mathrm{C}$. The thermometer was installed in pocket 3 filled with a water-ethylene glycol mixture. The initial mixture was poured into cube 1 through refrigerator 5 . The test mixture was heated by a flexible electric heater mounted on the outer surface of cube 1. The mixture was brought to a boil, and the boiling point was recorded as the value that remained unchanged for $15 \mathrm{~min}$ after the unit entered the mode. Simultaneously with fixing the temperature, the liquid phase was sampled from the bottom of the overflow tube 7 to clarify the composition of the boiling mixture.

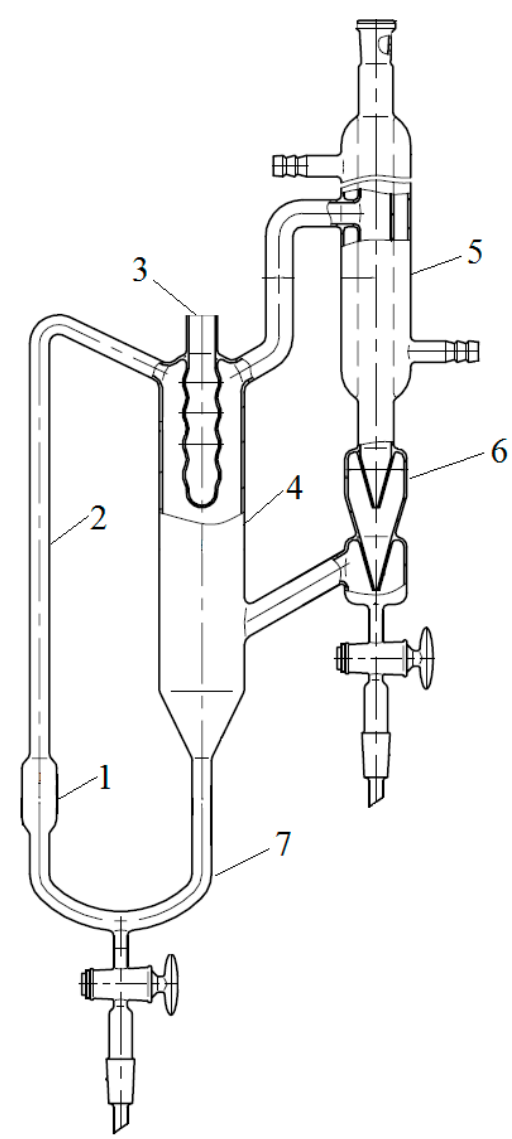

Scheme 1. Swietoslavsky ebulliometer: 1-cube; 2-Cottrell pump; 3-pocket for a thermometer; 4-separation space; 5-refrigerator; 6-drop counter; 7-overflow tube. 


\subsection{Phase Equilibrium Experiments}

To conduct experimental studies on the phase equilibrium of vapor-liquid in the alcohol-water-AEBA system, an approach based on the method of open evaporation was used, described in the work [19]. This approach provides a qualitative and quantitative assessment of the effect of the addition of an extractant on the conditions of phase equilibrium in an azeotropic mixture in a certain concentration range.

To conduct experimental studies on the phase equilibrium of vapor-liquid, an IKA-RV 10 digital rotary evaporator was used. The experimental technique and the evaluation of the results obtained are described in detail in the work [19].

\subsection{Phase Equilibrium Calculation}

To calculate the activity coefficients of the components of the mixture, the UNIFAC model was used [21]. The UNIFAC model is a universal pseudo-chemical equation for calculating the activity coefficients of the components of a solution based on data on the functional groups that make up the molecules of substances. This makes it possible to predict the conditions of vapor-liquid and liquid-liquid phase equilibrium for systems that have not been studied experimentally. Within the UNIFAC model, the activity rate is determined as follows:

$$
\ln \gamma_{i}=\ln \gamma_{i}^{C}+\ln \gamma_{i}^{R}
$$

The first term is called the combination contribution, and the second is called the residual. The value of the combination contribution depends only on the solution composition, as well as on the volume and surface of its constituent groups:

$$
\ln \gamma_{i}^{C}=\ln \frac{\Phi_{i}}{x_{i}}+\frac{z}{2} q_{i} \ln \frac{\theta_{i}}{\Phi_{i}}+l_{i}-\frac{\Phi_{i}}{x_{i}} \sum_{j} x_{j} l_{j}
$$

where $x_{i}$ is the component molar fraction of the in the solution; $\Phi_{i}$ and $\theta_{i}$ are the volume and surface fractions of a component in a solution:

$$
\theta_{i}=\frac{q_{i} x_{i}}{\sum_{j} q_{j} x_{j}} ; \Phi_{i}=\frac{r_{i} x_{i}}{\sum_{j} r_{j} x_{j}}
$$

The parameters of the pure components $r_{i}$ and $q_{i}$ characterize the molecular Van der Waals volumes and surface areas of the molecules, respectively. These parameters are determined by summing the group parameters of the volume $(R)$ and surface $(Q)$ :

$$
r_{j}=\sum_{k} v_{k}^{(i)} R_{k} ; q_{i}=\sum_{k} v_{k}^{(i)} Q_{k}
$$

where $v_{k}^{(i)}$ is an integer and determines the number of groups of type $k$ in molecule $i$.

The residual (energy) part of the activity coefficient in group models is represented by the sum of the contributions of the groups included in the molecule:

$$
\ln \gamma_{i}^{R}=\sum v_{k}^{(i)}\left(\ln \Gamma_{k}-\ln \Gamma_{k}^{(i)}\right),
$$

where $\Gamma_{k}$-residual activity coefficients of the group $(k)$ in solution; $\Gamma_{k}^{(i)}$ is the residual activity coefficients of the group $(k)$ in some comparative solution containing only type $i$ molecules. 
The activity coefficients of the group in the solution $\Gamma_{k}$ and $\Gamma_{k}^{(i)}$ are determined by the equation:

$$
\ln \Gamma_{k}=Q_{k}\left[1-\ln \left(\sum_{m} \theta_{m} \psi_{m k}\right)-\sum_{m} \frac{\theta_{m} \psi_{k m}}{\sum_{n} \theta_{n} \psi_{n m}}\right]
$$

where $\theta_{m}$ is the surface fraction of group $m$, and the sums include all the different groups:

$$
\theta_{\mathrm{m}}=\frac{Q_{m} X_{m}}{\sum_{n} Q_{n} X_{n}}
$$

where $X_{m}$ is the molar fraction of group $m$ in the mixture.

The group interaction parameter $\psi_{m n}$ is determined by the equation:

$$
\psi_{m n}=\exp \left(-\frac{U_{m n-U_{n n}}}{R T}\right)=\exp \left(-\frac{a_{m n}}{T}\right)
$$

where $a_{m n}$-characterizes the interaction between groups $n$ and $m$; for each group-group interaction, two parameters $a_{m n} \neq a_{m n}$ are used.

The UNIFAC group constituent method allows one to calculate the properties of various substances using a limited number of parameters characterizing the contributions of individual atoms or groups. Therefore, this method requires dividing the molecule into some standard set of groups.

\subsection{Simulation of the Extractive Distillation Process}

Modeling of the extractive distillation process of water-alcohol mixtures was carried out in the UniSim package (UniSim Design Academic Program). The calculations were carried out by the theoretical tray method. AEBA-TEG was investigated as a hypothetical component through the UNIFAC framework. The UNIFAC model was used to calculate the activity coefficients of the mixture components.

\section{Results}

3.1. Vapor-Liquid Equilibrium in Aqueous Solutions of Alcoholsin the Presence of AEBA

The synthesis of AEBA is carried out according to the following scheme (Figure 1):

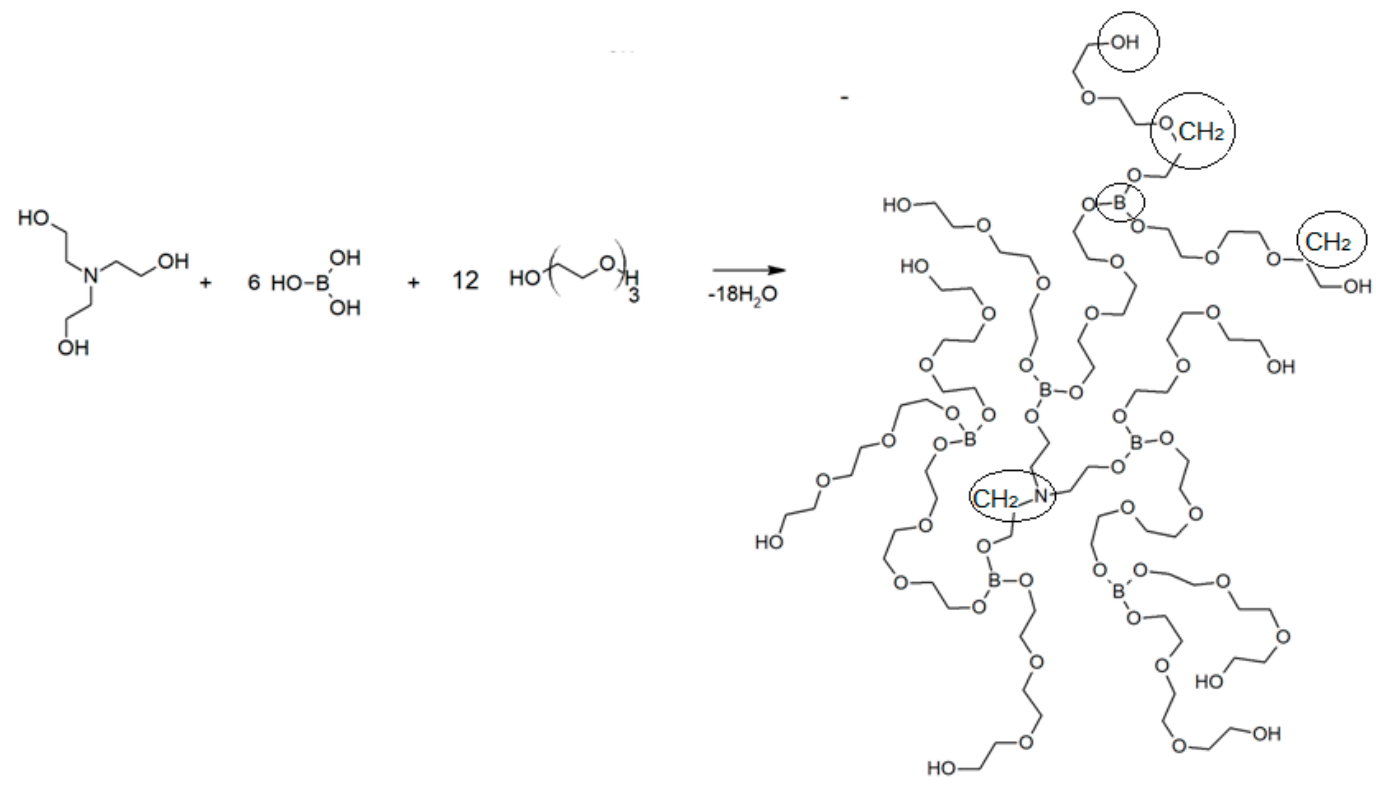

Figure 1. Scheme of synthesis of aminoethers of boric acid based on triethylene glycol AEBA-TEG. 
Glycols of various structures can be used for synthesis. In this work, variants with di- and tri-ethylene glycol (DEG and TEG) are considered, which makes it possible to obtain AEBA-DEG and AEBA-TEG, respectively. The UNIFAC model was used to describe the conditions of phase equilibrium in the alcohol-water-AEBA systems [21]. In this case, the activity coefficients were calculated from the group constituents parameters of the mixture molecules. AEBA molecules synthesized with various glycols differ only in the number of groups of the same type, the parameters of which can be determined based on specific AEBA, for example, AEBA-DEG and AEBA-TEG. In this case, the UNIFAC model has the potential to predict the conditions of phase equilibrium in aqueous alcohol solutions with AEBA of different molecular composition.

Within the UNIFAC model framework, molecules of substances are separated into group components. For water molecules and various alcohols, such a division has already been proposed [21]. Here it is proposed to divide the AEBA molecules into the following groups: $\mathrm{B}$-boron group, $\mathrm{CH}_{2}$-alkane group, $\mathrm{OCH}_{2}$-ether group, $\mathrm{NCH}_{2}$-amine-3d group, and $\mathrm{OH}$-alcohol group. The details of the split are shown in Figure 1. Thus, AEBA-TEG consists of $35-\mathrm{CH}_{2}, 42-\mathrm{OCH}_{2}, 6-\mathrm{B}, 9-\mathrm{OH}$ and 1- $\mathrm{NCH}_{2}$ groups, and AEBA-DEG consists of $23-\mathrm{CH}_{2}, 30-\mathrm{OCH}_{2}, 6-\mathrm{B}, 9-\mathrm{OH}$ and $1-\mathrm{NCH}_{2}$ groups. The molecular weights of AEBA-DEG and AEBA-TEG are 1470 and 1998, respectively.

Analysis of the literature [21,22] and the most complete database on the group interaction parameters for the UNIFAC model in the form of UNIFAC Matrix 2020 presented in the Dortmund Data Bank (DDB) [23] showed the absence of data on the boron group. Therefore, in this work, based on the available experimental data, the geometric parameters of the boron group and the interaction energy parameters of this group with other groups of the considered solutions were determined. These are $\mathrm{B}-\mathrm{CH}_{2}, \mathrm{~B}-\mathrm{OCH}_{2}, \mathrm{~B}-\mathrm{NCH}_{2}, \mathrm{~B}-\mathrm{OH}$, and $\mathrm{B}-\mathrm{H}_{2} \mathrm{O}$.

To determine the configurational contribution (2) to the activity coefficient (1), the group parameters $R$ and $Q$ data are required, which are related to the values of the Van der Waals group volume $V_{k}$ and the surface area $A_{k}$ (Van der Waals group volume and surface areas) [21,24]:

$$
R_{k}=\frac{V_{\omega_{k}}}{15.17} ; Q_{k}=\frac{A_{\omega_{k}}}{2.5 \cdot 10^{9}}
$$

The value of the Van der Waals radii $r_{W}$ for the boron atom was determined in different sources [25-27] in the range 1.65-1.92 $\mathrm{A}^{0}$. Here, the value $r_{W}=1.8 \mathrm{~A}^{0}$ was taken for boron. Hence, the values $R_{K}=0.9371$ and $Q_{K}=0.9809$.

The group interaction parameters $a_{m n}$ in the group interaction parameter $\psi_{m n}(8)$ were determined from the experimental VLE data using a regression analysis algorithm based on the least squares method. For binary systems, the objective function is:

$$
\begin{gathered}
F=\sum_{k}^{N}\left[y_{\mathrm{K}}^{E}-y_{\mathrm{K}}^{C}\right]^{2} \rightarrow \min \\
y^{c}=\frac{x \ln (\gamma) P^{s}(T)}{P}
\end{gathered}
$$

here $y$ and $x$ are the concentrations of component in vapor and liquid, respectively; $P^{S}(T)$ is the saturated vapor pressure of the pure component; superscripts $E$ and $C$ designate experimental and calculated data; $k$ and $N$ are the number and quantity of experimental points, respectively.

The available data on vapor-liquid equilibrium (VLE data) for binary solutions of borates were analyzed. DDB analysis [28] showed that VLE data with borate solutions are rather limited. VLE data turned out to be useful for binary systems trimethyl borate-cyclohexane [29] and trimethyl borate-n-heptane [30]. These data were used to determine the parameters $\mathrm{B}-\mathrm{CH}_{2}, \mathrm{~B}-\mathrm{OCH}_{2}$ (Table 1). The data on the saturated vapor pressure of trimethyl borate (TMB), cyclohexane, and n-heptane were taken from the NIST database [31]. To demonstrate the description reliability of the phase equilibrium condition, Figure 2 shows a comparison of the calculated data according to the UNIFAC model, 
obtained with new parameters (Table 1), with known experimental data. The average deviation of the calculated concentrations from the experimental ones was 3\%, and for temperatures, it was $-1 \%$.

Table 1. Boron group interaction parameters (Bn).

\begin{tabular}{ccc}
\hline $\boldsymbol{m}$ & $\boldsymbol{a}_{\boldsymbol{m} n}$ & $\boldsymbol{a}_{\boldsymbol{n}}$ \\
\hline $\mathrm{CH}_{2}$ & 170.60 & -384.58 \\
$\mathrm{OCH}_{2}$ & 405.99 & 1825.92 \\
$\mathrm{OH}$ & -281.82 & -722.30 \\
$\mathrm{NCH}_{2}$ & 113.96 & -13.53 \\
$\mathrm{H}_{2} \mathrm{O}$ & -237.83 & -1136.35 \\
\hline
\end{tabular}

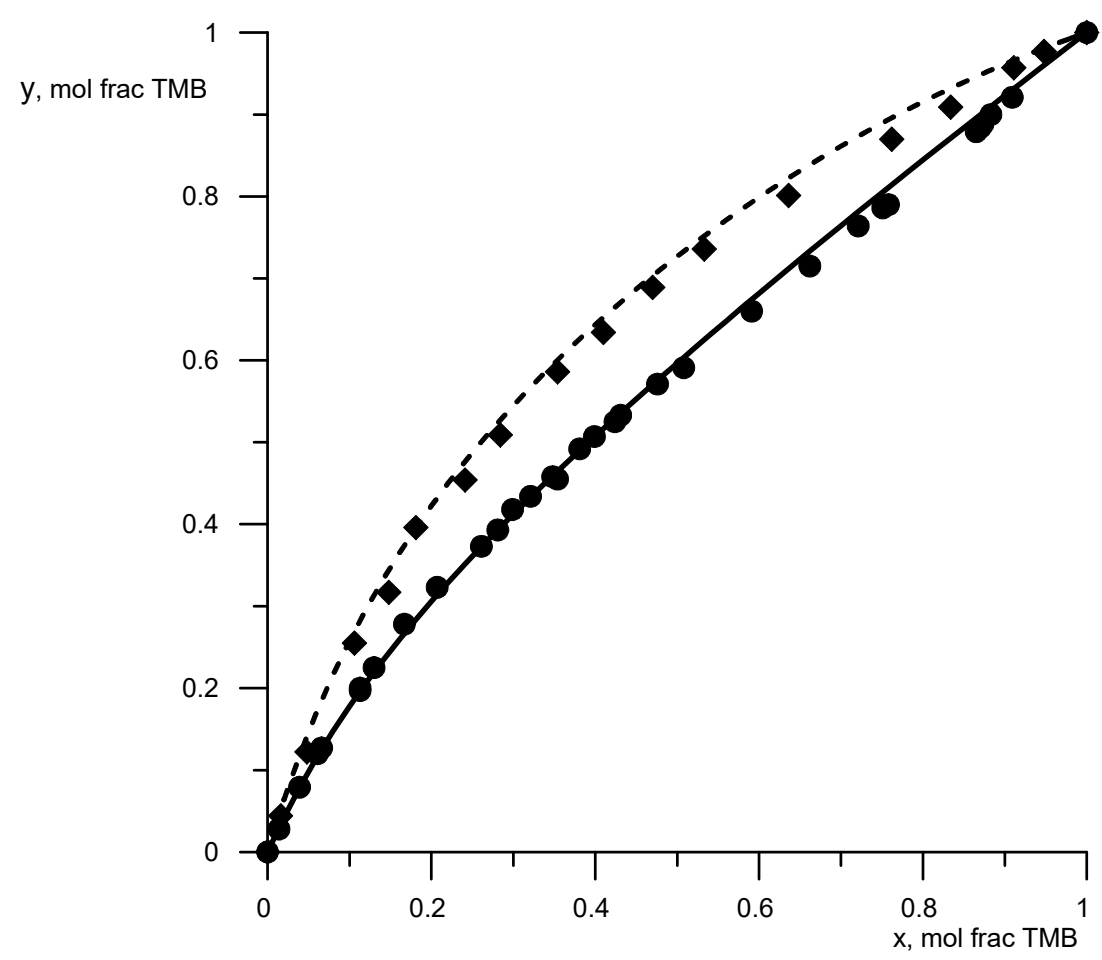

Figure 2. Equilibrium compositions of vapor and liquid for a mixture of trimethyl borate-cyclohexane (circles, solid line) and trimethyl borate-n-hexane (rhombuses, dashed lines). Geometric figures are experimental data, and lines are calculated data.

The remaining unknown parameters were determined from the experimental data on the boiling points at atmospheric pressure of binary solutions AEBA-DEG/AEBA-TEG-ethanol, AEBA-DEG/AEBA-TEG-isopropanol, and AEBA-DEG/AEBA-TEG-water. The experimental data were obtained using the Swietoslawski setup [20]. The accuracy of determining the boiling points of pure water and alcohols using this setup was $0.5 \%$. Figure 3 shows the boiling points of aqueous solutions of AEBA. Aqueous solutions of ionic liquids have similar behavior, but with a reduced role of the non-volatile character of the compound. As previously revealed, the volatility of AEBA-DEG/AEBA-TEG in comparison with water and alcohol can be neglected [19]; therefore, the activity coefficient of water or alcohol in a mixture with AEBA can be determined from the known boiling point $T_{S}$ of the mixture as

$$
\ln (\gamma)=\frac{P}{x P^{s}(T s)}
$$


First, the parameters $\mathrm{B}-\mathrm{NCH}_{2}$ and $\mathrm{B}-\mathrm{OH}$ were determined by the boiling points of AEBA-DEG/AEBA-TEG-ethanol and AEBA-DEG/AEBA-TEG-isopropanol. Then, the parameter B- $\mathrm{H}_{2} \mathrm{O}$ was determined from the boiling point of AEBA-DEG/AEBA-TEG-water. The results of comparing the calculated and experimental data are shown in Figures 3 and 4 . The average discrepancy was $1 \%$.

The defined parameters of the boron group interaction are presented in Table 1.

The adequacy verification of the description of the vapor-liquid equilibrium of aqueous-alcoholic solutions in the presence of AEBA was carried out by comparing the calculated and experimental data on open evaporation.

Open evaporation equation:

$$
y(x)^{*}=-\frac{d x}{d(e)}(1-e)+x
$$

where $e=P / L_{0} ; P$ is the amount of distillate withdrawn; $L_{0}$ is the initial mass of the mixture in the still.

The experimental setup and the experimental procedure are described in detail in [19].

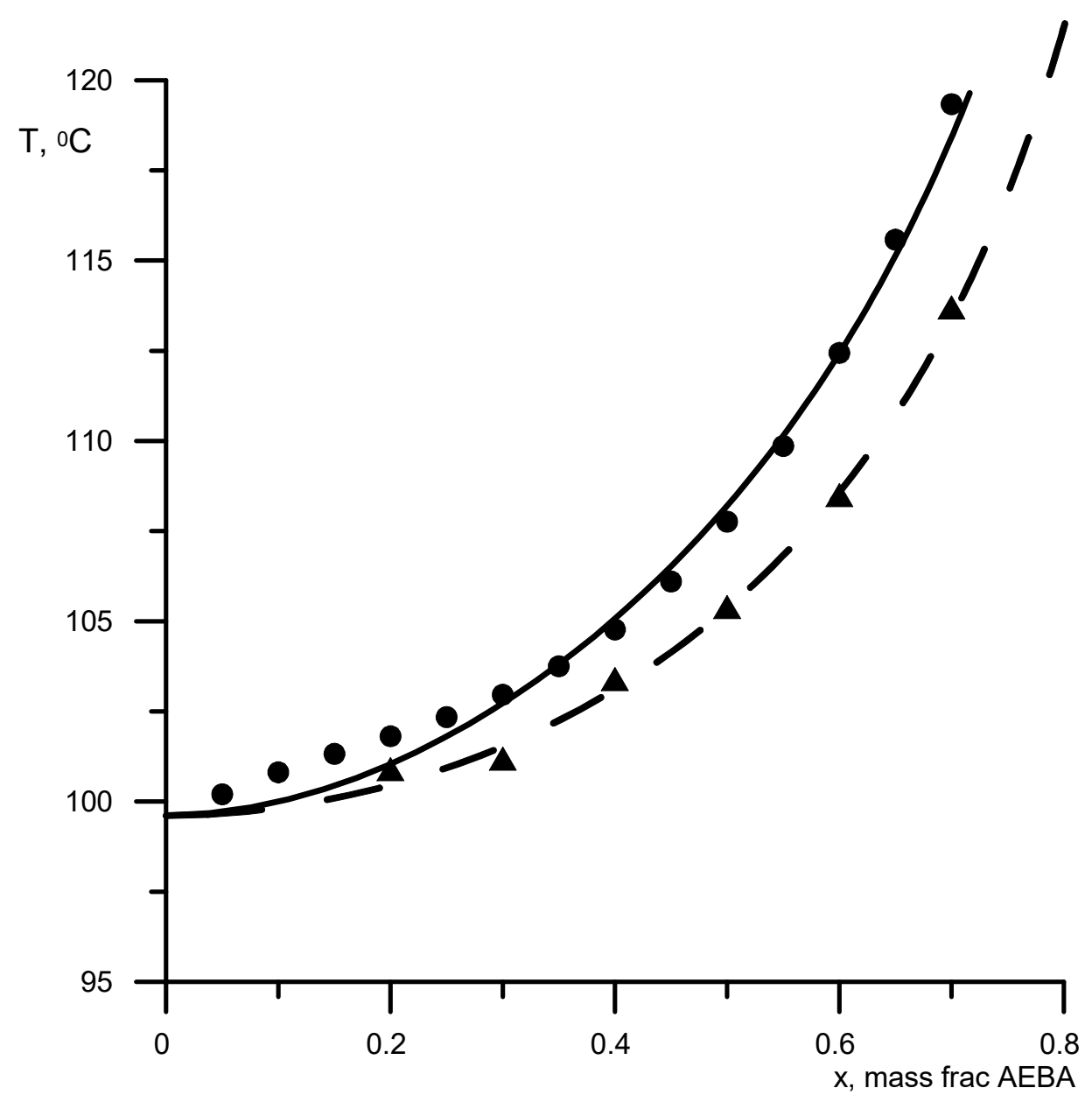

Figure 3. Boiling points of aqueous AEBA solutions at atmospheric pressure. Geometric figures are experimental values (circles-AEBA-diethylene glycol (DEG); triangles-AEBA-TEG), and lines are calculated values.

Figure 5 shows the results of comparison of the curves of residual compositions obtained for the ethanol-water mixture at different concentrations of AEBA-TEG. A good reproduction of the experimental data calculations using the UNIFAC model with the proposed parameters can be seen. Figure 5 also shows the curves of residual compositions for the ethanol-water mixture in the absence of AEBA for comparison, which shows the effect of AEBA on the relative volatility of ethanol. Experiments 
and calculation results have shown that the residual composition of the ethanol-water mixture depends on the type of added AEBA (based on TEG or DEG). The effect of AEBA-DEG on the relative volatility of ethanol is, on average, $10 \%$ stronger. To assess the efficiency of using AEBA, we compared the coefficients of the relative volatility of ethanol in an aqueous solution in the presence of AEBA, glycerol and propylene glycol at their content of $30 \mathrm{wt} \%$ (Figure 6).

The relative volatility coefficient was determined as:

$$
\alpha_{12}=\frac{y_{1}}{x_{1}} / \frac{y_{2}}{x_{2}}
$$

where the $y_{1}$ and $y_{2}$ equilibrium concentration of ethanol and water in steam above the solution was determined by the UNIFAC model; $x_{1}$ and $x_{2}$ are concentrations of ethanol and water in solution.

Figures 6 and 7 show a comparison of the AEBA separation ability with known entrainers currently used to separate azeotropic alcohol mixtures (glycerol and propylene glycol). The results in Figures 6 and 7 show that in the entire range of the considered compositions, with the addition of AEBA, the relative volatility coefficient of alcohol is 1.5-2 times higher, especially in the region of high alcohol concentrations near the azeotrope point. The dependence nature of the relative volatility coefficient in the presence of AEBA is similar to some imidazole ILs ([mim][DMP] and [mim][Cl]).

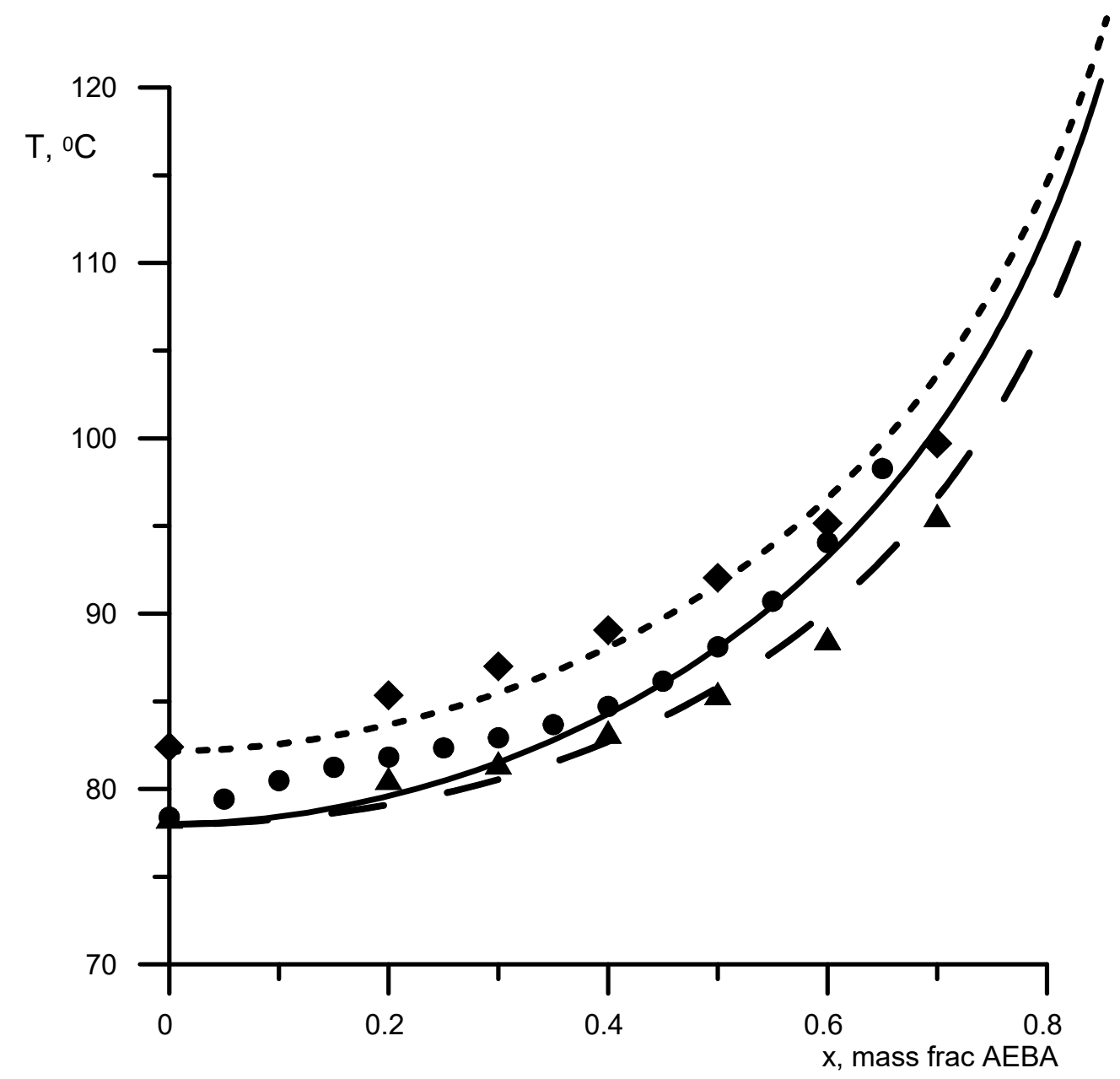

Figure 4. Boiling points of alcoholic solutions of AEBA at atmospheric pressure. Geometric figures are experimental values (circles-AEBA-DEG-ethanol; triangles-AEBA-TEG-ethanol; rhombuses-AEBA-TEG-isopropanol), and lines are calculated values. 


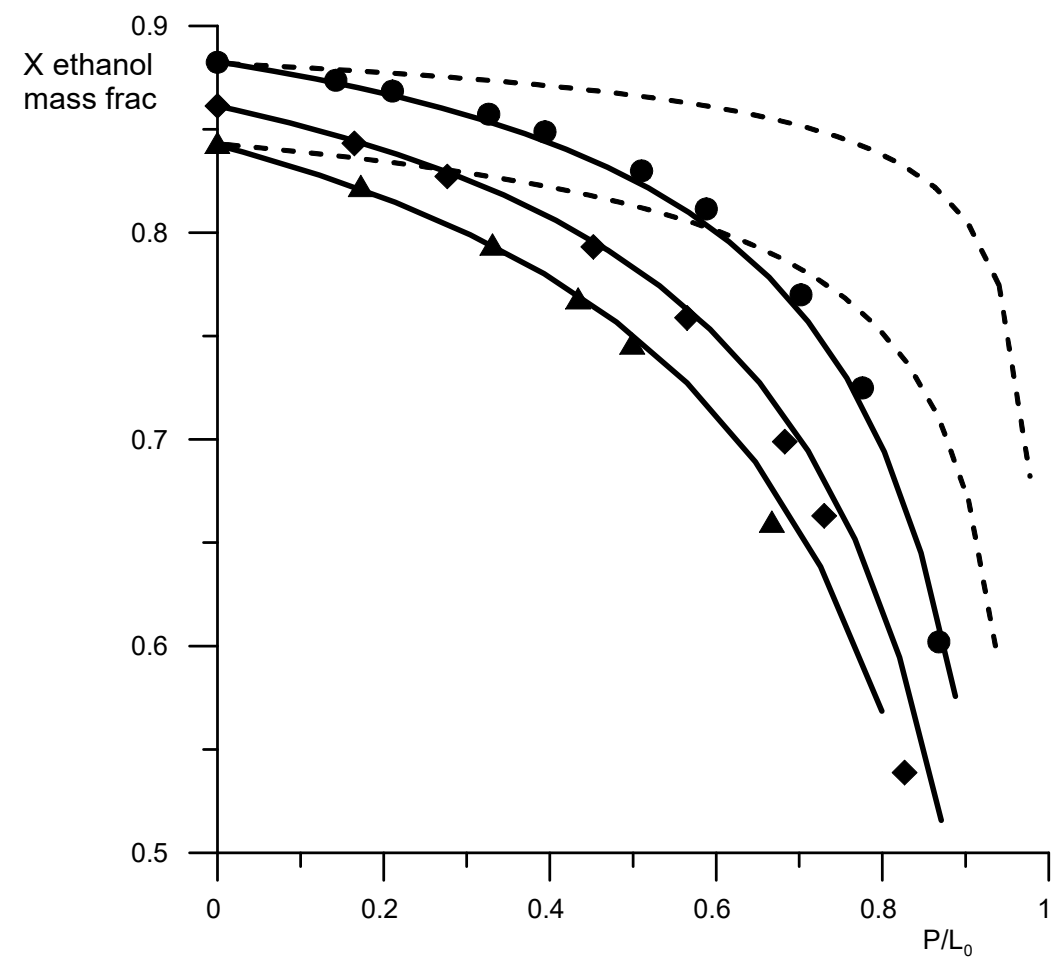

Figure 5. Residual curves for the ethanol-water-AEBA-TEG mixture. Geometric figures are experimental values (circles-AEBA-TEG $20 \mathrm{wt} \%$, rhombuses-AEBA-TEG $40 \mathrm{wt} \%$, triangles-AEBA-TEG $60 \mathrm{wt} \%$ ), and continuous lines are calculated values. Dotted lines-calculated values for the ethanol-water mixture without AEBA.

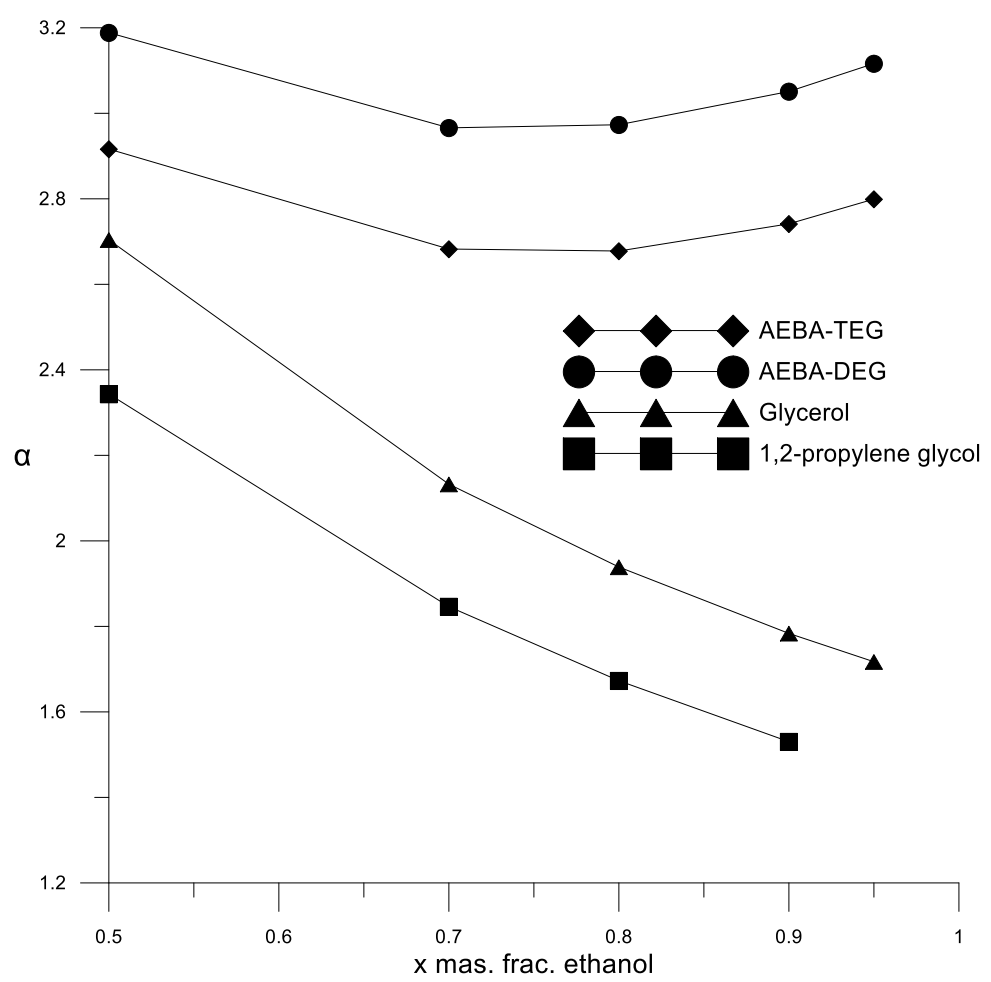

Figure 6. The coefficient of the components relative volatility of the ethanol-water mixture in the presence of various extractants. 


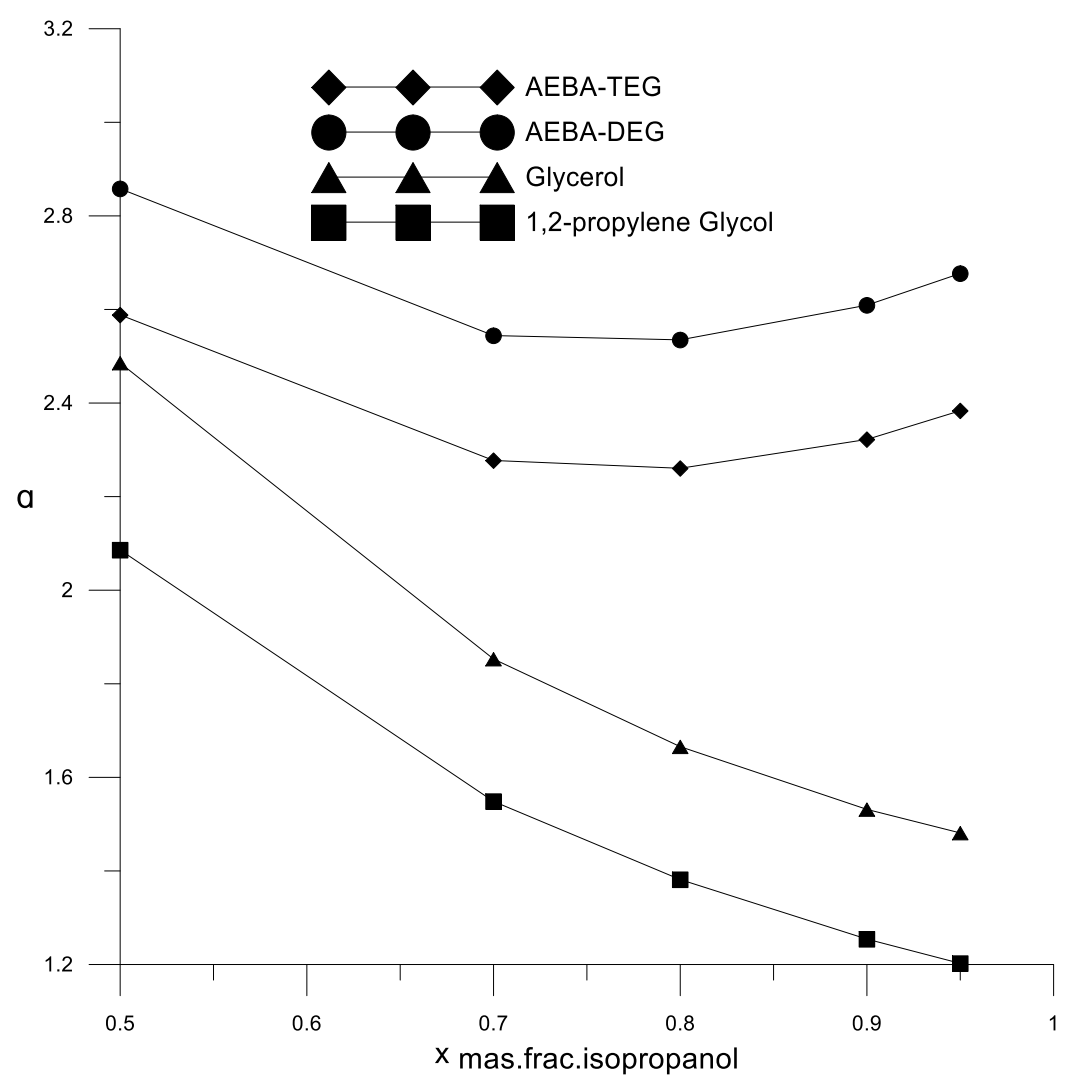

Figure 7. The coefficient of the components relative volatility of the isopropanol-water mixture in the presence of various extractants.

\subsection{The Process of Extractive Distillation of Ethanol-Water Mixtures Using AEBA-TEG as an Extractant}

To analyze the process of extractive rectification of an ethanol-water mixture, AEBA-TEG was chosen as an extractive agent. The choice was determined by the fact that AEBA-DEG and AEBA-TEG have similar indicators of influence on the relative volatility of water and alcohol (Figures 6-9), but AEBA-TEG has a higher temperature of thermal decomposition [19]. Since the purpose of the research was to assess the energy and material costs of carrying out the process without the need to perform design calculations, the calculations of the rectification process were carried out on the basis of the theoretical tray model [32]. The theoretical tray method takes into account only the thermodynamic factor and makes it possible to determine the fundamental possibility and estimate the complexity of the mixture separation. The actual dimensions of the column depend on the rate of mass transfer between the boundary and the core of the phases. The mass transfer coefficient is usually characterized by the mass transfer coefficient or Murphree efficiency. These values largely depend on the physical properties (viscosity, diffusion and density) of the vapor and liquid phases. During distillation, when the viscosity of the liquid phase is low $(1-10 \mathrm{mPa} \cdot \mathrm{s})$, the mass transfer in the vapor phase is limiting. The presence of AEBA can significantly increase the viscosity of the liquid mixture. However, as shown by measurements [19] for conditions in a distillation column, where the concentration of AEBA in the liquid mixture is about $30-50 \mathrm{wt} \%$ and at a temperature of about $80{ }^{\circ} \mathrm{C}$, the viscosity of the liquid phase will not exceed $2 \mathrm{mPa} \cdot \mathrm{s}$. It is hoped that under these conditions, the main resistance to mass transfer will remain in the vapor phase. Thus, the design diagram of the distillation column (Figure 10) was built on the basis of a system of material and heat balance equations, as well as equations for vapor-liquid phase equilibrium. Activity coefficients were calculated using the UNIFAC model with the parameters given in Table 1. 


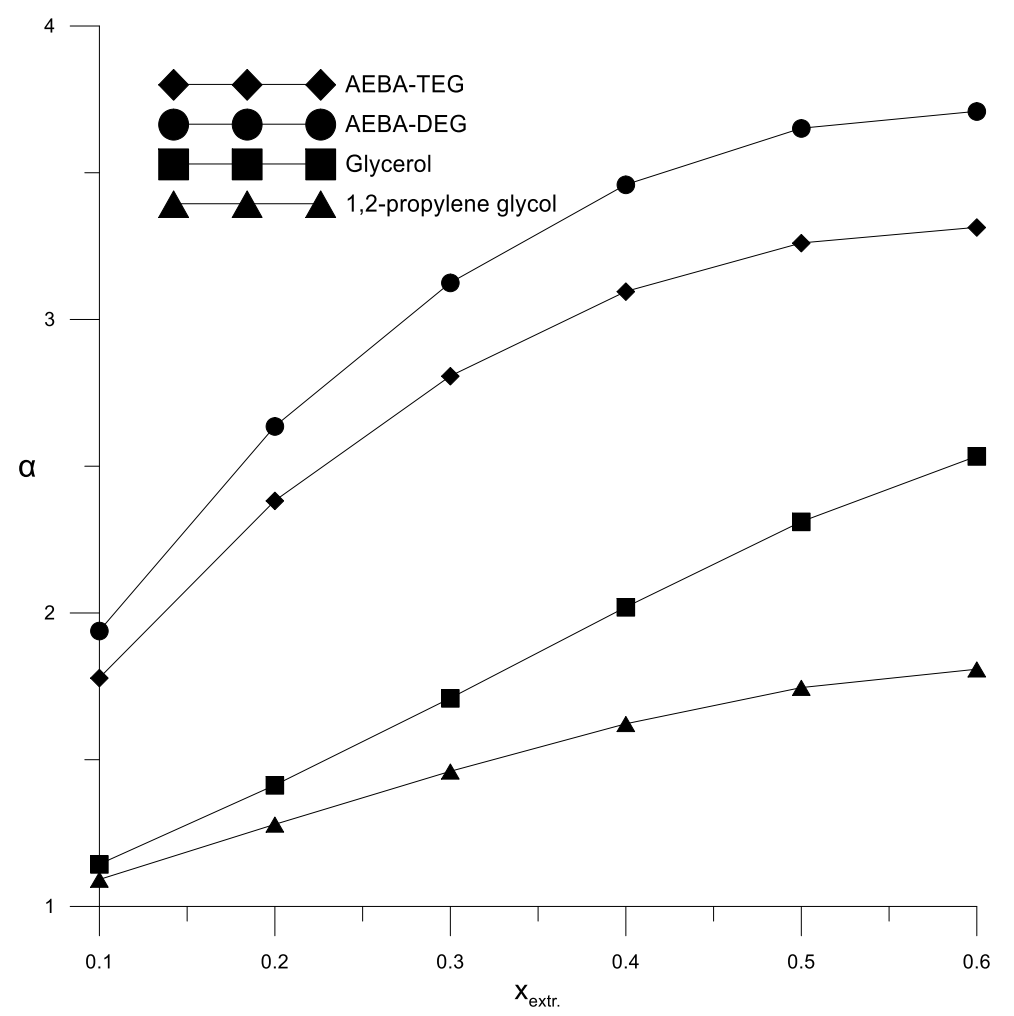

Figure 8. The coefficient of relative volatility depending on the concentration of the extractant at the azeotropic point of the ethanol-water mixture.

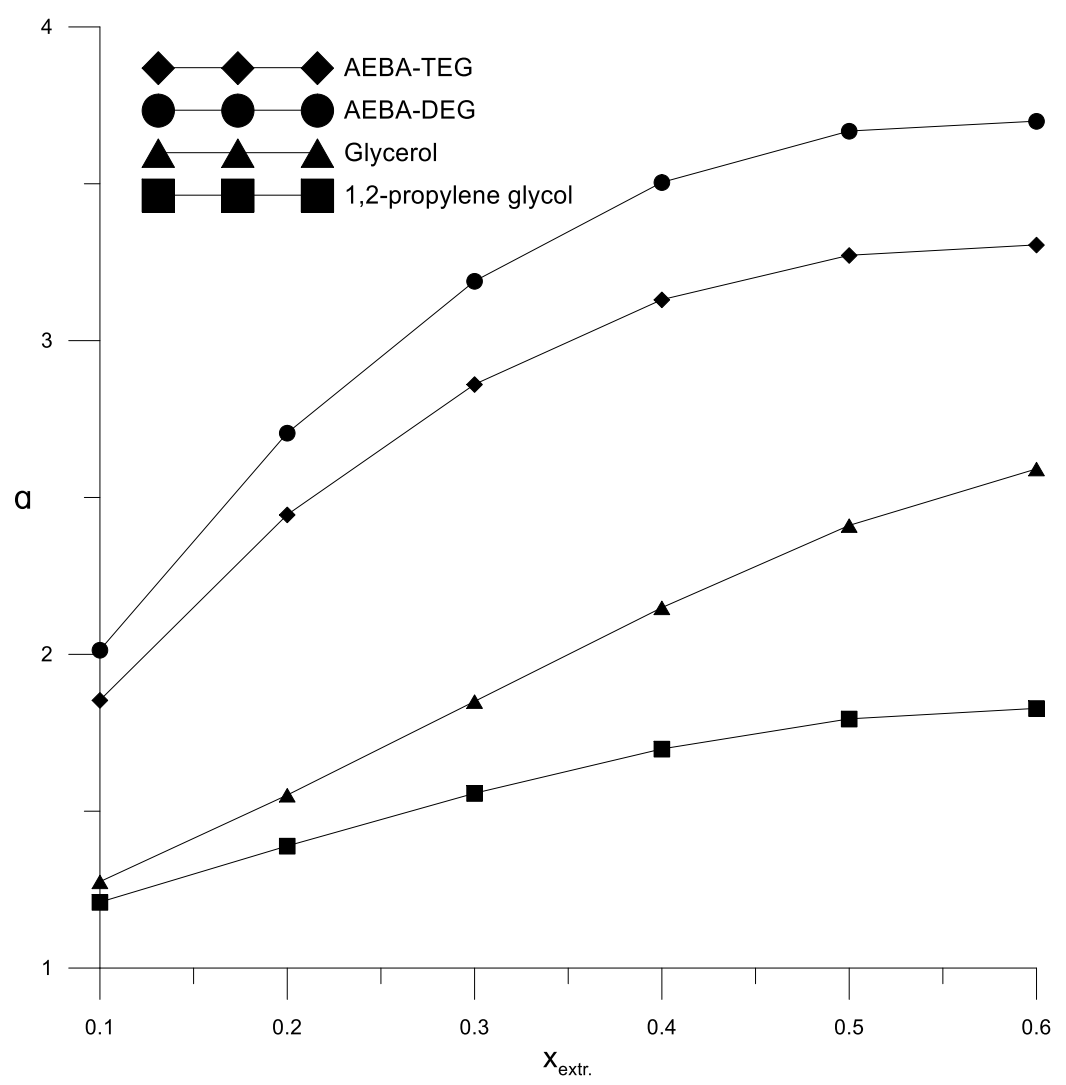

Figure 9. The coefficients of the relative volatility depending on the concentration of the extractant at the azeotropic point of the isopropanol-water mixture. 


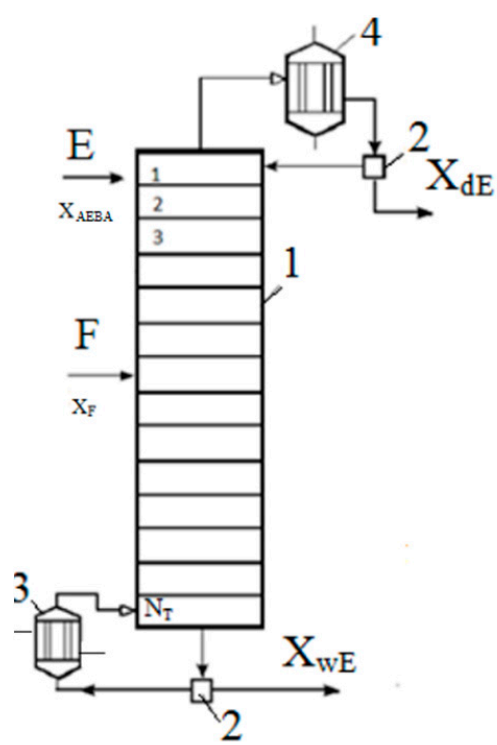

Figure 10. Calculation scheme of the extractive distillation column: 1—distillation column, 2-separator, 3-boiler, 4-reflux condenser.

Initially, the influence of the extractant amount supplied, reflux ratio and number of theoretical trays on the distillate composition was investigated. For the calculations, the following conditions were used:

- $\quad$ Feed composition $X_{F}$ (0.9 mass fraction of ethanol; 0.1 mass fraction of water), which is close to the azeotropic point. The required alcohol content in the distillate $X_{\mathrm{dE}}=>99.5 \mathrm{wt} \%$; alcohol in the still $X_{\mathrm{We}}<10^{-7} \mathrm{wt} \%$.

- The pressure in the column was equal to atmospheric pressure; the pressure drop across the column was neglected.

- $\quad \mathrm{N}_{\mathrm{T}}$ is the total number of trays; $\mathrm{N}_{\mathrm{F}}$ is feed tray. Due to the fact that the volatility of AEBA is negligible, the extractant flow was fed to the first tray $\mathrm{N}_{\mathrm{E}}=1$.

- Complete condensation of vapor occurred in the reflux condenser; complete evaporation of the liquid mixture occurred in the cube.

- $\quad \mathrm{R}$ is the reflux ratio.

The flow rate of the initial mixture $\mathrm{F}$ was conventionally assumed to be $100 \mathrm{~kg} / \mathrm{h}$, since the calculation results are influenced not by the flow rate itself, but by its ratio to the extractant flow rate ef $=\mathrm{E} / \mathrm{F}$. The feed tray was selected from the condition of the maximum concentration of ethanol in the distillate under other specified conditions.

Figure 11 shows the effect of reflux ratio and extractant flow rate on distillate composition in a column with 18 theoretical trays. It can be seen that the required alcohol content in the distillate $(99.5 \mathrm{wt} \%)$ is achieved for the extractant consumption starting from ef $=0.3$. With an increase in the consumption of the extractant, a smaller amount of reflux is required to achieve a given composition of the distillate. For all considered cases, the value of the reflux ratio was less than 1 . The dependences from Figure 9 have a characteristic maximum associated with the fact that with an increase in the reflux ratio, the amount of reflux supplied increases, and when mixed with the extractant, the concentration of the latter decreases.

Figure 12 shows the calculations for three different values of the number of theoretical trays in the column: $\mathrm{N}_{\mathrm{T}}=18 ; \mathrm{N}_{\mathrm{T}}=25$ and $\mathrm{N}_{\mathrm{T}}=30$. It is seen that with an increase in the number of trays, the required composition of the distillate can be obtained at a lower consumption of the extractant. At the same time, increasing the number of trays by more than 25 is impractical due to a slight change in the reflux ratio, which makes it possible to reduce capital costs. 


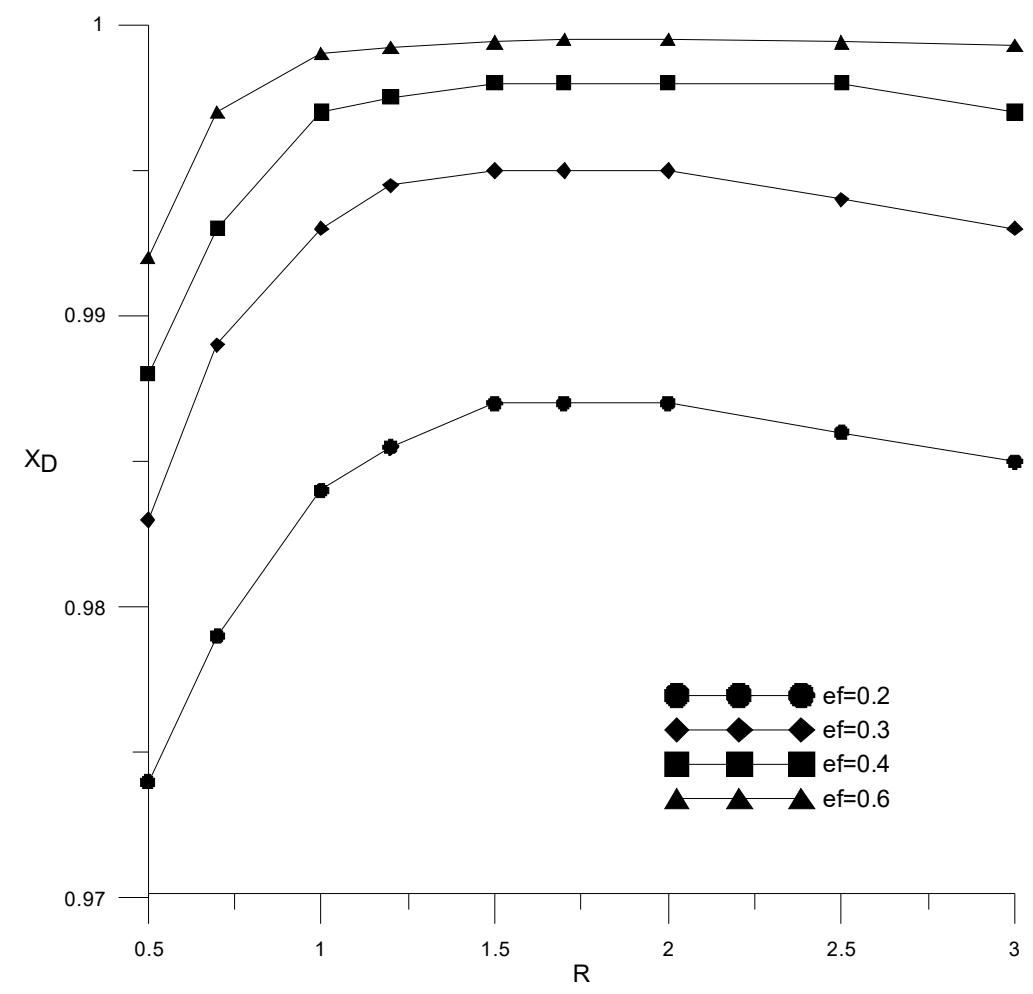

Figure 11. Influence of reflux ratio on ethanol concentration in distillate with different amounts of extractant.

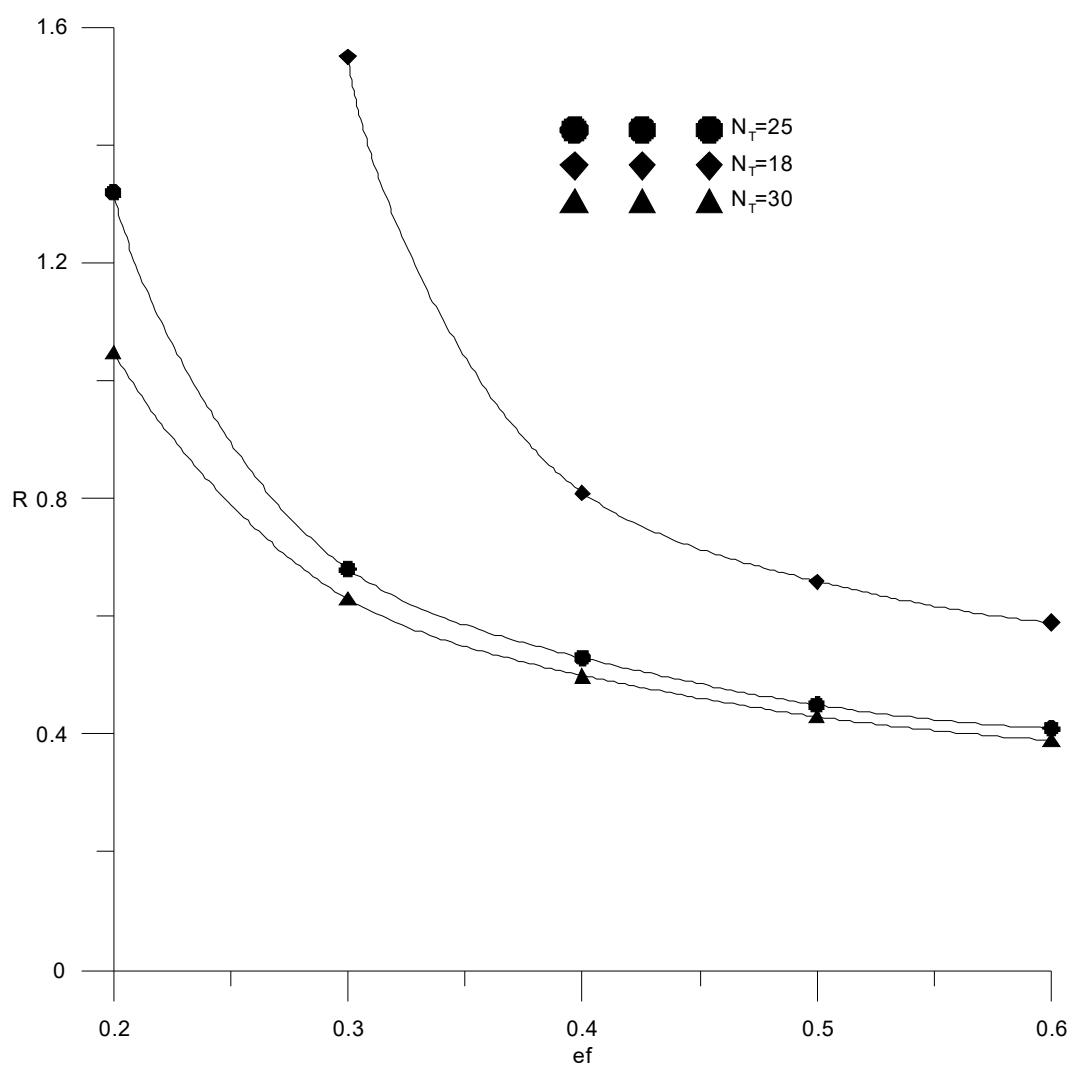

Figure 12. Change in reflux ratio from the amount of extractant supplied with a different number of trays (NT). 
The technology for the dehydration of ethanol, together with an extractive rectification unit, should include a unit for recovering the extractant from its aqueous solution. To extract AEBA from an aqueous solution, various processes can be used, as well as their combination [33]. Often, various types of distillation are used for these purposes: distillation under vacuum, stripping with inert gas, and molecular distillation. The efficiency of distillation processes can be increased by combining them with membrane separation or adsorption. The choice of a specific scheme for AEBA regeneration requires a comparative technical and economic analysis. Since the key task in this work was to study the process of extractive rectification, we did not perform such an analysis. Distillation under vacuum was chosen for the AEBA regeneration, as it is simple enough for modeling and traditionally used in many studies of extractive schemes for the dehydration of alcohols. The latter allows the comparison of costs for the entire ethanol recovery scheme. Considering that the volatility of AEBA-TEG compared to water is negligible, the regeneration process can be carried out by simple distillation. However, it is necessary to bear in mind a significant increase in the boiling point of the AEBA solution at a low water concentration and the onset temperature of the AEBA-TEG, which is about $190^{\circ} \mathrm{C}$ [19]. Figure 13 shows saturation pressure isotherms versus water concentrations in a solution with AEBA-TEG. The most acceptable conditions for the industrial version of the AEBA-TEG aqueous solution distillation process are temperatures in the range of $110-150^{\circ} \mathrm{C}$ and a pressure of $0.05-0.3 \mathrm{~atm}$.

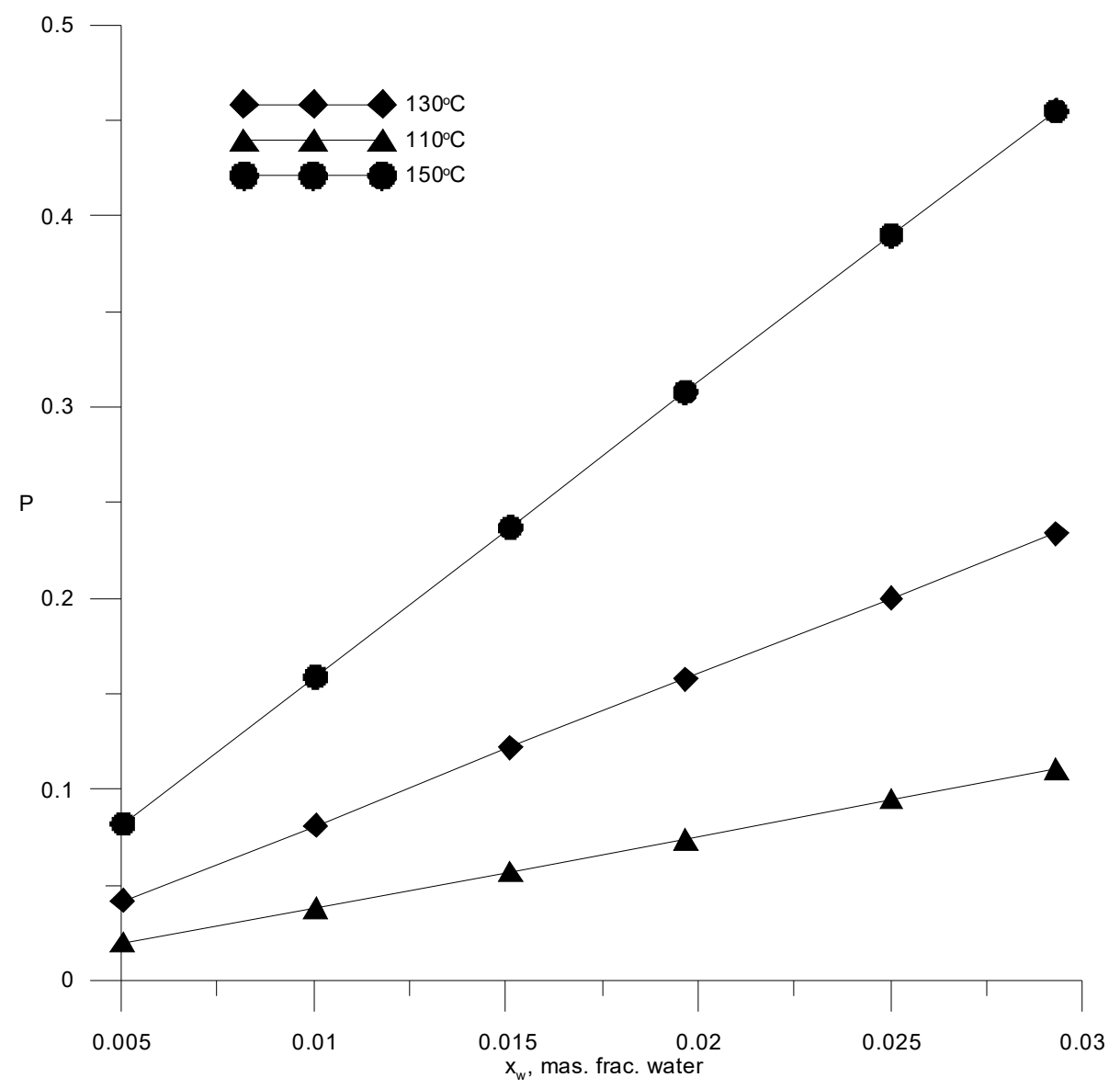

Figure 13. Isotherms of saturated water vapor pressure over a binary water-AEBA-TEG solution, depending on the composition.

The residual water content in the regenerated AEBA-TEG will be $1-3 \mathrm{wt} \%$. The water content in the extractant will negatively affect the separation efficiency of the water-alcohol mixture; however, with an increase in the water content in the extractant, the costs of its regeneration will decrease. These costs are associated with the depth of the vacuum and the temperature of the heating medium. The total 
cost of obtaining dehydrated alcohol by the extractive rectification technology can be represented by the following function:

$$
Q=\alpha E+\beta(R+1)+\eta N(R+1)+\lambda P_{V}
$$

The following are the cost items:

- $\quad E$ is the amount of fresh extractant supplied, which is equal to the possible losses for the regeneration scheme. We will assume that these costs are negligible compared to others.

- $\quad(R+1)$ is the costs of heat in the evaporator cube of the extractive rectification column.

- $\quad N(R+1)$ capital costs associated with the size of the extractive rectification column; the number of trays $N$ is proportional to the height of the column; $(R+1)$ is proportional to the steam flow rate, which determines the diameter of the column.

- $\quad P_{V}$ is the costs of extractant regeneration associated with the depth of the vacuum and the corresponding material and operating costs.

- $\quad \alpha, \beta, \eta$ and $\lambda$ are normalization coefficients.

If the composition of the distillate and the cube is specified by the alcohol-water content, then the cost Function (15) will depend on three variables: the specific consumption of the extractant, the number of trays or the reflux ratio in the extractive rectification column, and the water content in the extractant after regeneration. It is easy to see that the cost items for heat in the cube of the evaporator of the extractive rectification column and for regeneration of the extractant are proportional to the reflux ratio and water content in the extractant, respectively. Therefore, here, we provided studies of the independent variables' influence on capital costs, defined as $N(R+1)$. Figures 14 and 15 show the isolines of costs at constant flow rates of the extractant and the number of trays, respectively, in the absence of water in the extractant. In this case, the cost function of two variables does not have a minimum; the cost value decreases monotonically with an increase in the extractant flow rate and a decrease in the number of plates. In this case, it is necessary to be guided by a reasonable consumption of the extractant. The situation changes significantly in the presence of water in the extractant.

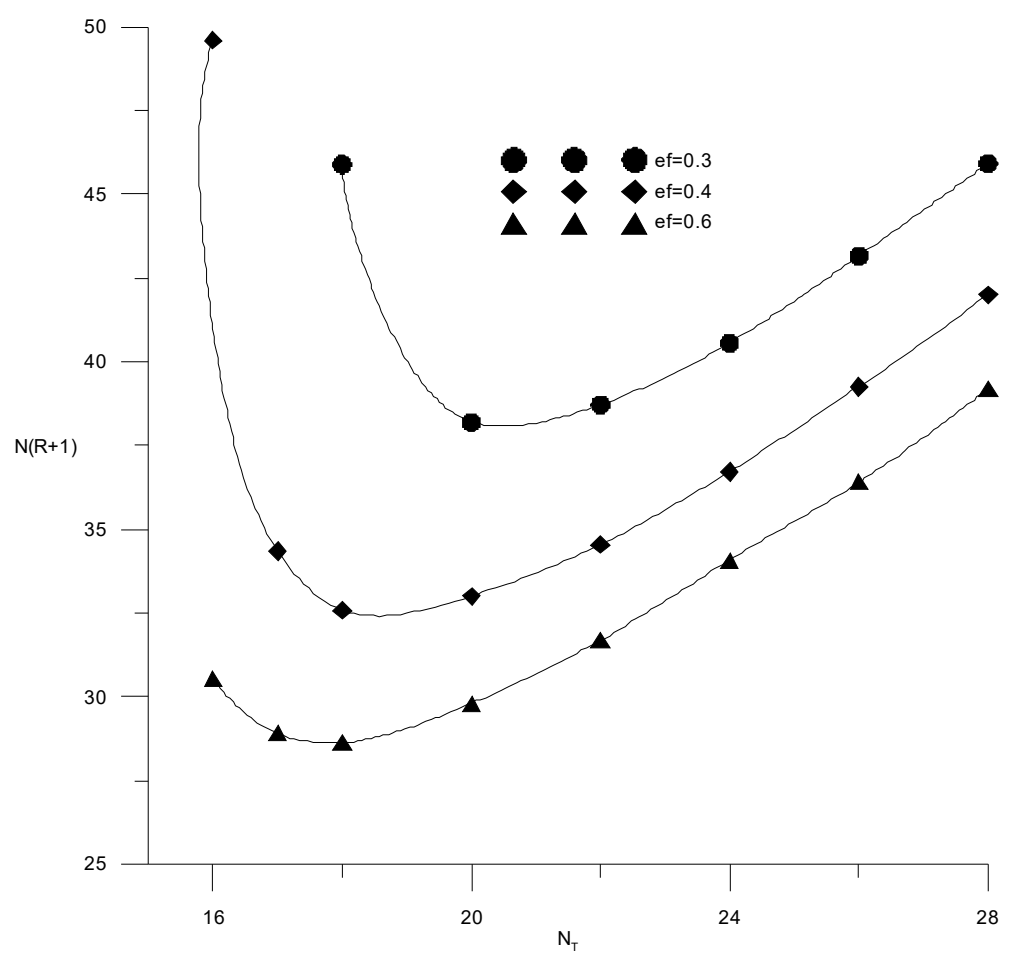

Figure 14. Capital costs for extractive rectification from the number of trays in the column at different flow rates of fresh extractant. 


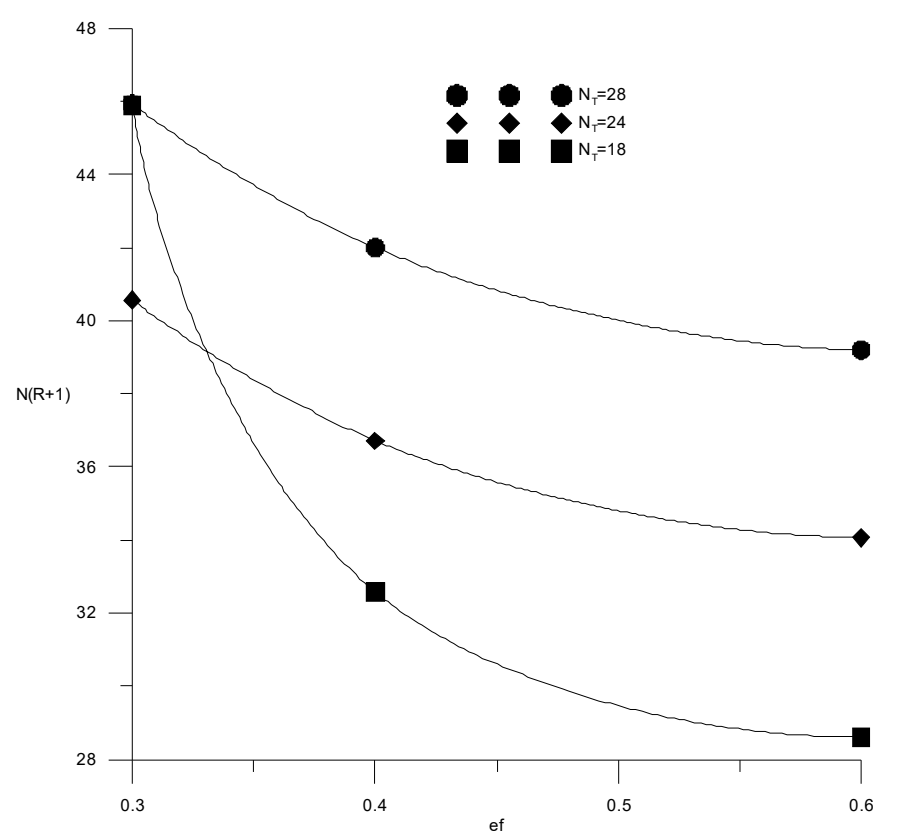

Figure 15. Capital costs for extractive rectification from the fresh extractant consumption with a different number of trays in the column.

Figures 16 and 17 show similar calculation results for the case of water content in the extractant of $-3 \mathrm{wt} \%$. It can be seen that minima appear on the cost function. The minimum occurs when the water content in the extractant is more than $1 \%$. Its size and position depend on the water content in the extractant. For example, for $2 \mathrm{wt} \%$ of water in the extractant minimum, capital costs correspond to the relative consumption of the extractant 0.45 and 20 theoretical trays, and for $3 \mathrm{wt} \%$ of water, relative consumption of the extractant 0.4 and 24 theoretical trays. Thus, with an increase in water content from 0 to $3 \mathrm{wt} \%$, costs are doubled, and with an increase in the concentration of water in the extractant from 2 to $3 \mathrm{wt} \%$, costs increase by $50 \%$. Thus, it is necessary to analyze the possible compensation for the increase in capital costs for extractive rectification by reducing the cost of solvent regeneration.

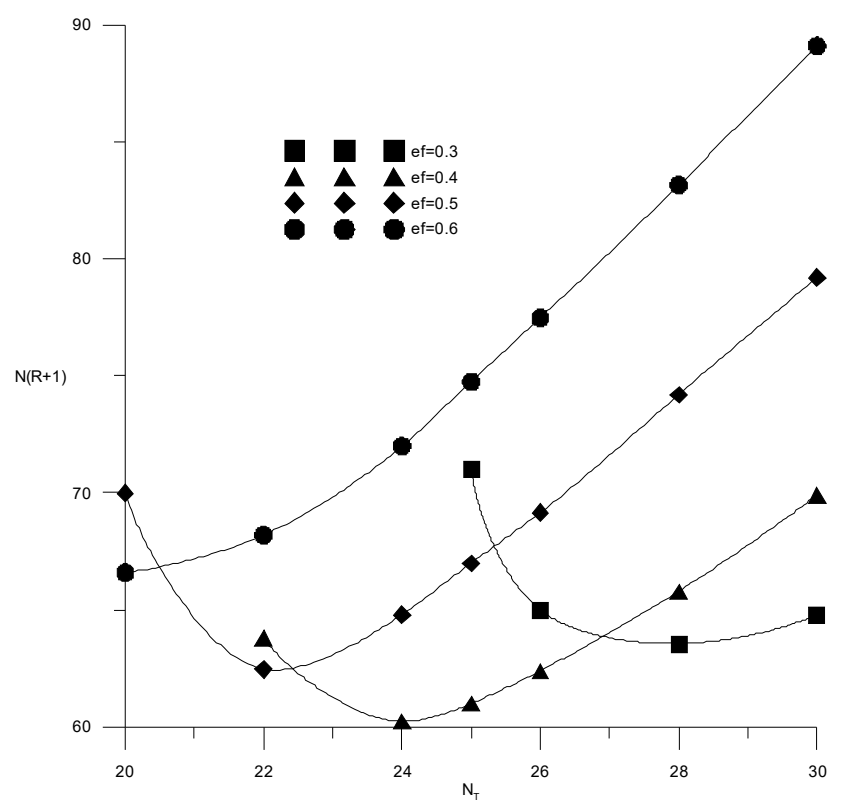

Figure 16. Capital costs for extractive rectification of the trays number in the column at different flow rates of the extractant with a water content of $3 \mathrm{wt} \%$. 


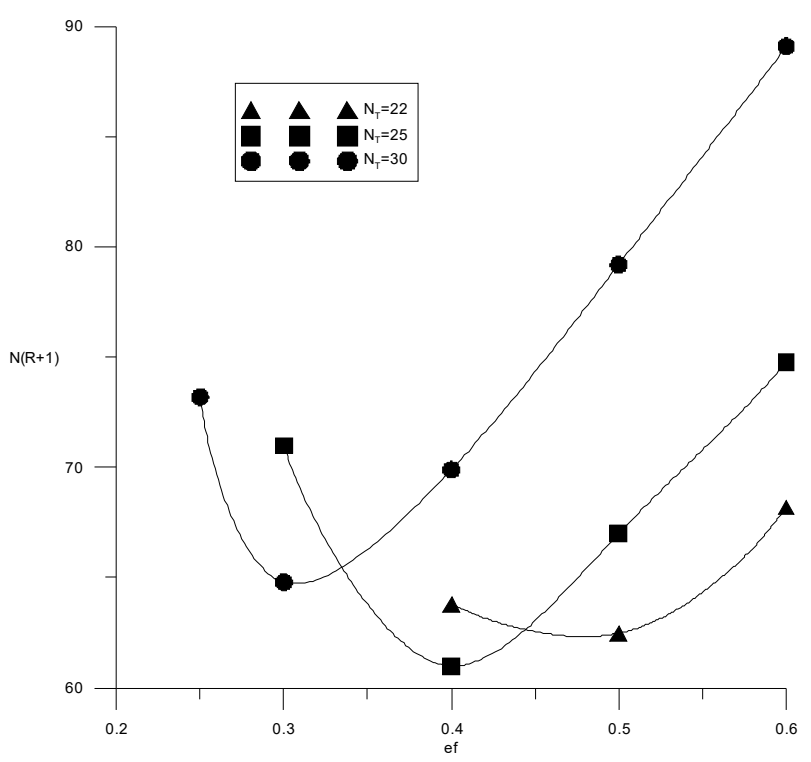

Figure 17. Capital costs for extractive rectification from the flow rate of the extractant with a water content of $3 \mathrm{wt} \%$ with a different number of trays in the column.

Figure 18 shows the process flow diagram of ethanol dehydration. The process of obtaining ethanol with a water content of $0.005 \mathrm{wt} \%$ takes place in the distillation column C-1, where the extractant AEBA-TEG is fed to the first tray. An aqueous solution of the extractant with alcohol content of $10^{-5} \mathrm{wt} \%$ is removed from the bottom of the column C-1. Further, the extractant is fed to the simple distillation apparatus C-2, where the AEBA is dehydrated. At the outlet of the cube, the pressure increases and the temperature drops to the level of these indicators on the first tray of column C-1. Since at low concentrations of water the AEBA solution has a high viscosity, it is possible to reduce it by mixing with the reflux stream from the $\mathrm{C}-1$ column.

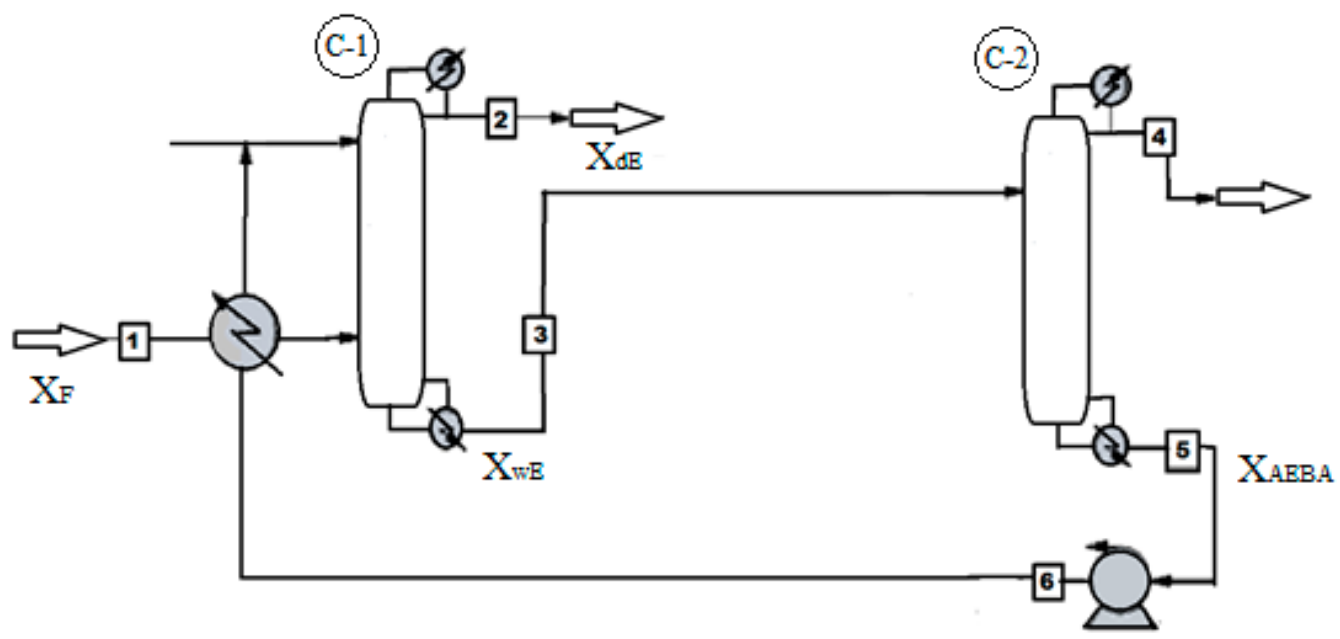

Figure 18. Technology system of ethyl alcohol separation from an aqueous solution process with AEBA-TEG as extractant.

The results of calculating the main parameters of the technological scheme (Figure 18) for different variants of the water content in the extractant are presented in Table 2. The values of the trays number and the extractant flow rate were selected from the condition of the minimum cost function shown in Figures 15-17. For comparison, the same table shows the results of energy consumption per $1 \mathrm{~kg}$ of dried ethanol when using glycerol [34] and glycols [35] as an extractant, and for azeotropic rectification [36]. 
Table 2. Results of modeling the process of ethyl alcohol separation from an aqueous solution.

\begin{tabular}{|c|c|c|c|c|c|c|c|c|c|}
\hline Extractant & ef & $\mathbf{N}_{\mathrm{T}}$ & $\mathrm{Np}$ & $\mathrm{Ne}$ & $\mathbf{R}$ & $\begin{array}{c}X_{\mathrm{dE}} \\
\text { Mass Frac. }\end{array}$ & $\begin{array}{c}X_{\mathrm{wE}} \\
\text { Mass Frac. }\end{array}$ & P (vac.), Bar & $\begin{array}{l}\text { Energy } \\
\text { Consum., } \\
\mathrm{mJ} / \mathrm{kg}\end{array}$ \\
\hline $\begin{array}{l}\text { AEBA-TEG } \\
(99.99 \mathrm{wt} \%)\end{array}$ & 0.4 & 18 & 8 & 1 & 0.81 & 0.995 & $10^{-7}$ & 0.1 & 1.74 \\
\hline AEBA-TEG (98 wt \%) & 0.45 & 20 & 10 & 1 & 1.06 & 0.995 & $10^{-7}$ & 0.1 & 1.98 \\
\hline AEBA-TEG (97 wt \%) & 0.4 & 24 & 15 & 1 & 1.56 & 0.995 & $10^{-7}$ & 0.1 & 2.56 \\
\hline $\begin{array}{c}\text { Glycerol } \\
(99.99 \mathrm{wt} \%) \text { [34] }\end{array}$ & 1 & 18 & 10 & 2 & 0.35 & 0.998 & 0.005 & 0.1 & 1.63 \\
\hline $\begin{array}{l}\text { Ethylene glycol } \\
(99.99 \mathrm{wt} \%) \text { [35] }\end{array}$ & 0.71 & 24 & 12 & 2 & 0.5 & 0.998 & 0.004 & 0.1 & 1.76 \\
\hline Pentane (azeotrop. Dist.) [36] & & & & & & & & & 6.3 \\
\hline
\end{tabular}

As can be seen from the table, the highest energy consumption corresponds to the process of azeotropic rectification. For the scheme with extractive rectification, the energy consumption per $1 \mathrm{~kg}$ of alcohol turns out to be similar for different extractants. In this case, for AEBA, the required amount of extractant per $1 \mathrm{~kg}$ of alcohol is 1.5 times less than for other extractants.

\section{Conclusions}

In this work, AEBA were considered as promising extractants for the extraction of alcohols from aqueous solutions using rectification. The conditions of vapor-liquid equilibrium in the AEBA-DEG/AEBA-TEG-aqueous solution of ethanol/isopropanol systems were modeled on the basis of the model for the UNIFAC activity coefficients. For this, a variant of the division of AEBA molecules into group components has been proposed, and the previously unknown geometric and energy parameters of the boron group have been identified. The identification of the parameters was carried out according to the known data of vapor-liquid equilibrium in binary solutions of borates, as well as from the boiling points of AEBA solutions in water, ethanol, and isopropanol measured in this work. The adequacy of the calculation of the activity coefficients in the three-component mixture AEBA-DEG/AEBA-TEG-aqueous solution of ethanol/isopropanol was confirmed by comparing the solution of the open evaporation equation with the experimental data of the residue curve. Thus, the obtained matrix of UNIFAC parameters (UNIFAC Matrix) makes it possible to calculate and predict the activity coefficients of the components of aqueous-alcoholic solutions in the presence of AEBA of various molecular structures with satisfactory accuracy.

Modeling of the extractive rectification process of an ethanol-water mixture with an extractant AEBA-TEG for the production of ethanol with a purity of $99.5 \mathrm{wt} \%$ was conducted. Additionally, the behavior of the cost function on the reflux ratio (the number of theoretical trays) and the relative consumption of the extractant and the water content in it were investigated. It has been shown that the water content in the extract increases the costs of rectification and leads to the appearance of a minimum on the cost function, which must be taken into account when designing industrial technologies. Modeling of the process flow diagram for the production of ethanol with a water content of $0.5 \mathrm{wt} \%$ was conducted, and regeneration of the extractant AEBA-TEG was carried out. It is shown that the energy consumption per $1 \mathrm{~kg}$ of alcohol is similar for different extractants (AEBA, glycerol, glycols); however, when using AEBA, the amount of extractant per $1 \mathrm{~kg}$ of alcohol is required 1.5 times less.

Author Contributions: A.V.K. conceived of the study, coordinated the study, carried out data and results analysis, carried out sequence alignments and drafted the manuscript; A.V.M., designed the study, coordinated and participated in the experimental part of the study and carried out the results analysis; A.R.K. carried out the separation experiment, carried out phase equilibrium experiments, carried out sequences of the study and provided necessary calculations; S.E.D. carried out synthesis lab work and participated in the manuscript drafting; I.M.D. coordinated lab work, carried out sequences, analyzed the obtained results and critically revised the manuscript. All authors have read and agreed to the published version of the manuscript. 
Funding: This research was funded by the Ministry of Science and Higher Education of the Russian Federation grant number 075-00315-20-01 "Energy saving processes of liquid mixtures separation for the recovery of industrial solvents".

Conflicts of Interest: There are no conflict to declare.

\section{Abbreviations}

$\begin{array}{ll}\text { AEBA } & \text { Aminoethers of boric acid } \\ \text { IL } & \text { Ionic liquid } \\ \text { DEG } & \text { diethylene glycol } \\ \text { TEG } & \text { triethylene glycol } \\ \text { AEBA-DEG } & \text { aminoethers of boric acid based on diethylene glycol } \\ \text { AEBA-TEG } & \text { aminoethers of boric acid based on triethylene glycol } \\ \text { VLE } & \text { Vapor-liquid equilibrium } \\ \text { TMB } & \text { Trimethyl borate }\end{array}$

\section{References}

1. State Standard: GOST P 56146-2014 Denatured Ethanol Used as a Fuel Component for Spark igniTion Engines-M; National Standard of the Russian Federation: Moscow, Russia, 2015; p. 27.

2. Stabnikov, V.N. Distillation and Rectification of Ethyl Alcohol; Food industry: Moscow, Russia, 1969; 456p.

3. Furter, W.F. Extractive distillation by salt effect. Chem. Eng. Commun. 1992, 116, 35-40. [CrossRef]

4. Lei, Z.; Zhou, R.; Duan, Z. Process improvement on separating C4 by extractive distillation. Chem. Eng. J. 2002, 85, 379-386. [CrossRef]

5. Rongqi, Z.; Zhanting, D. Extractive Distillation with Salt in Solvent. Sci. Technol. 1999, 4, 1477-1479.

6. Lei, Z.; Wang, H.; Zhou, R.; Duan, Z. Influence of salt added to solvent on extractive distillation. Chem. Eng. J. 2002, 87, 149-156. [CrossRef]

7. Fu, J. Simulation of Salt-Containing Extractive Distillation for the System of Ethanol/Water/ Ethanediol/KAc. 1. Calculation of the VaporLiquid Equilibrium for the Salt-Containing System. Ind. Eng. Chem. Res. 2004, 43, 1274-1278. [CrossRef]

8. Fu, J. Simulation of Salt-Containing Extractive Distillation for the System of Ethanol/Water/Ethanediol/KAc. 2. Simulation of Salt-Containing Extractive Distillation. Ind. Eng. Chem. Res. 2004, 43, 1279-1283. [CrossRef]

9. Tiverios, P.G.; Van Brunt, V. Extractive Distillation Solvent Characterization and Shortcut Design Procedure for Methylcyclohexane-Toluene Mixtures. Ind. Eng. Chem. Res. 2000, 39, 1614-1623. [CrossRef]

10. Seiler, M.; Jork, C.; Kavarnou, A.; Arlt, W.; Hirsch, R. Separation of azeotropic mixtures using hyperbranched polymers or ionic liquids. AICHE J. 2004, 50, 2439-2454. [CrossRef]

11. Jin, Z.; Cong, D.; Chun, L.X. Isobaric Vapor-Liquid Equilibria for Ethanol-Water System Containing Different Ionic Liquids at Atmospheric Pressure. Fluid Phase Equilib. 2006, 242, 147-153.

12. Jiang, X.C.; Wang, J.F.; Li, C.X. Vapor Pressure Measurement for Binary and Ternary Systems Containing Methanol, Ethanol and Ionic Liquid Ethy-3-Ethylimidazolium Diethylphosphate. J. Chem. Thermodyn. 2007, 39, 841-846. [CrossRef]

13. Calvar, N.; González, B.; Macedo, E.A.; Domínguez, Á. Study of the behaviour of the azeotropic mixture ethanol-water with imidazolium-based ionic liquids. Fluid Phase Equilibria 2007, 259, 51-56. [CrossRef]

14. Wang, J.; Li, C.-X.; Wang, Z.-H.; Li, Z.-J.; Jiang, Y.-B. Vapor pressure measurement for water, methanol, ethanol, and their binary mixtures in the presence of an ionic liquid 1-ethyl-3-methylimidazolium dimethylphosphate. Fluid Phase Equilibria 2007, 255, 186-192. [CrossRef]

15. Zhao, J.; Jiang, X.-C.; Li, C.; Wang, Z.-H. Vapor pressure measurement for binary and ternary systems containing a phosphoric ionic liquid. Fluid Phase Equilibria 2006, 247, 190-198. [CrossRef]

16. Ge, Y.; Zhang, L.; Yuan, X.; Geng, W.; Ji, J. Selection of ionic liquids as entrainers for separation of (water + ethanol). J. Chem. Thermodyn. 2008, 40, 1248-1252. [CrossRef]

17. Wang, J.; Li, C.X.; Wang, Z.H. Measurement and Prediction of Vapor Pressure of Binary and Ternary Systems Containing 1-Ethyl-3-methylimidazolium Ethyl Sulfate. J. Chem. Eng. Data 2007, 52, 1307-1312. [CrossRef] 
18. Calvar, N.; Gonzalez, B.; Gomez, E.; Dominguez, A. Vapor-Liquid Equilibria for Ternary System Ethanol + Water + 1-Ethyl-3-Methylimidazolium Ethyl Sulfate and Corresponding Binary Systems Containing the Ionic Liquids at $101.3 \mathrm{kPa}$. J. Chem. Eng. Data 2008, 53, 820-825. [CrossRef]

19. Davletbaeva, I.M.; Klinov, A.V.; Khairullina, A.R.; Malygin, A.V.; Dulmaev, S.E.; Davletbaeva, A.R.; Mukhametzyanov, T.A. Organoboron Ionic Liquids as Extractants for Distillation Process of Binary Ethanol + Water Mixtures. Processes 2020, 8, 628. [CrossRef]

20. Swietoslawski, W. Azeotropy and Polyazeotropy; Macmillan Company: New York, NY, USA, 1963.

21. Reid, R.C.; Prausnitz, J.M.; Poling, B.E. The Properties of Gases and Liquids 1987, 4th ed.; McGraw-Hill: New York, NY, USA, 1987; p. 753, ISBN 10:0070517991.

22. Wittig, R.; Lohmann, J.; Gmehling, J. Vapor-Liquid Equilibria by UNIFAC Group Contribution. Revision and Extension. Ind. Eng. Chem. Res. 2003, 42, 183-188. [CrossRef]

23. Online UNIFAC Source. Available online: http://unifac.ddbst.de/unifac-matrix.html (accessed on 24 June 2020).

24. Abrams, D.S.; Prausnitz, J.M. Statistical thermodynamics of liquid mixtures: A new expression for the excess Gibbs energy of partly or completely miscible systems. AIChE J. 1975, 21, 116-128. [CrossRef]

25. Have you looked at the Journal of Physical Chemistry recently. Chem. Eng. News Arch. 1964, 42, 441. [CrossRef]

26. Badenhoop, J.K.; Weinhold, F. Natural steric analysis:Ab initiovan der Waals radii of atoms and ions. J. Chem. Phys. 1997, 107, 5422-5432. [CrossRef]

27. Mantina, M.; Chamberlin, A.C.; Valero, R.; Cramer, C.J.; Truhlar, D.G. Consistent van der Waals Radii for the Whole Main Group. J. Phys. Chem. A 2009, 113, 5806-5812. [CrossRef] [PubMed]

28. +Online Source: Dortmund Data Bank. Thermophysical Data for Process Design. Available online: http://ddbonline.ddbst.com/DDBSearch/onlineddboverview.exe (accessed on 24 June 2020).

29. Kraher, M.V.; Plank, C.A.; Laukhuf, W.L.S. Vapor-Liquid Equilibria of the System Trimethyl Borate (1)-n-Cyclohexane (2). J. Chem. Eng. Data 1986, 31, 387. [CrossRef]

30. Niswonger, D.S.; Plank, C.A.; Laukhuf, W.L.S. Vapor-liquid equilibria of the system trimethyl borate (1)-n-heptane (2). J. Chem. Eng. Data 1985, 30, 209-211. [CrossRef]

31. Online Source: NIST Standard Reference Database. Available online: https://webbook.nist.gov/chemistry/ (accessed on 24 June 2020).

32. Richardson, J.F.; Harker, J.H.; Backhurst, J.R. Particle Technology and Separation Processes. In Chemical Engineering, 5th ed.; Oxford Butterworth-Heinemann: Oxford, UK, 2003; Volume 2, p. 1231, ISBN 978-0-7506-4445-7.

33. Mai, N.L.; Ahn, K.; Koo, Y.-M. Methods for recovery of ionic liquids-A review. Process Biochem. 2014, 49, 872-881. [CrossRef]

34. Gil, I.D.; Gómez, J.M.; Rodríguez, G. Control of an extractive distillation process to dehydrate ethanol using glycerol as entrainer. Comput. Chem. Eng. 2012, 39, 129-142. [CrossRef]

35. Meirelles, A.; Weiss, S.; Herfurth, H. Ethanol dehydration by extractive distillation. J. Chem. Technol. Biotechnol. 2007, 53, 181-188. [CrossRef]

36. Kiss, A.A.; David, J.; Suszwalak, P.C. Enhanced bioethanol dehydration by extractive and azeotropic distillation in dividing-wall columns. Sep. Purif. Technol. 2012, 86, 70-78. [CrossRef]

Publisher's Note: MDPI stays neutral with regard to jurisdictional claims in published maps and institutional affiliations.

(C) 2020 by the authors. Licensee MDPI, Basel, Switzerland. This article is an open access article distributed under the terms and conditions of the Creative Commons Attribution (CC BY) license (http://creativecommons.org/licenses/by/4.0/). 